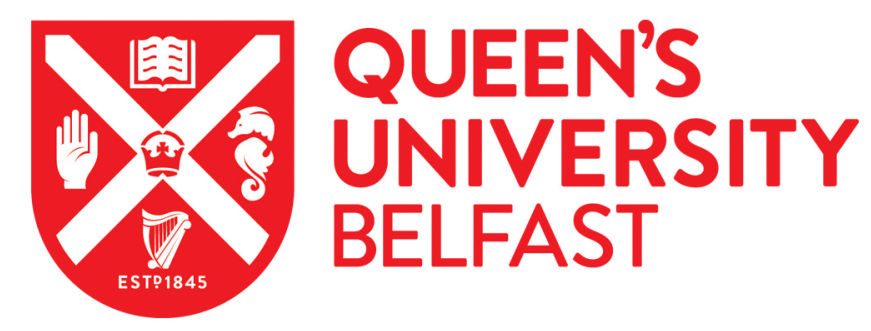

\title{
Scaling of continuous twin screw wet granulation
}

Osorio, J. G., Sayin, R., Kalbag, A. V., Litster, J. D., Martinez-Marcos, L., Lamprou, D. A., \& Halbert, G. W. (2017). Scaling of continuous twin screw wet granulation. AlChE Journal, 63(3), 921-932.

https://doi.org/10.1002/aic.15459

\section{Published in:}

AIChE Journal

\section{Document Version:}

Peer reviewed version

Queen's University Belfast - Research Portal:

Link to publication record in Queen's University Belfast Research Portal

\section{Publisher rights}

Copyright 2017 Wiley. This work is made available online in accordance with the publisher's policies. Please refer to any applicable terms of use of the publisher.

\section{General rights}

Copyright for the publications made accessible via the Queen's University Belfast Research Portal is retained by the author(s) and / or other copyright owners and it is a condition of accessing these publications that users recognise and abide by the legal requirements associated with these rights.

Take down policy

The Research Portal is Queen's institutional repository that provides access to Queen's research output. Every effort has been made to ensure that content in the Research Portal does not infringe any person's rights, or applicable UK laws. If you discover content in the Research Portal that you believe breaches copyright or violates any law, please contact openaccess@qub.ac.uk. 


\section{Scaling of Continuous Twin Screw Wet Granulation}

Juan G. Osorio ${ }^{1,2}$, Ridade Sayin ${ }^{1}$, Arjun Kalbag ${ }^{1}$, Laura Martinez-Marcos ${ }^{3}$, Dimitrios Lamprou ${ }^{3}$, Gavin Halbert ${ }^{3}$ and James D. Litster ${ }^{1,4 *}$

$5 \quad{ }^{1}$ School of Chemical Engineering, Purdue University, West Lafayette, IN 47907 USA

${ }^{2}$ Present address: Department of Chemical Engineering, Massachusetts Institute of Technology, Cambridge, MA 02139 USA

${ }^{3}$ Strathclyde Institute of Pharmacy and Biomedical Sciences (SIPBS), University of Strathclyde, Glasgow, UK

$10{ }^{4}$ Present Address: Department of Chemical and Biological Engineering, The University of Sheffield, Western Bank, Sheffield, South Yorkshire S10 2TN UK

\section{Journal: AIChE Journal - Particle Technology and Fluidization}

\section{Abstract}

15 Scaling rules were tested for a continuous twin screw wet granulation (TSG) process using three scales of twin screw granulators $(11 \mathrm{~mm}, 16 \mathrm{~mm}$ and $24 \mathrm{~mm}$ barrel diameter). This study also served to characterize the distributive feed screw (DFS) screw element as part of the screw configuration in the $16 \mathrm{~mm}$ and $24 \mathrm{~mm}$ twin screw granulators. This DFS screw configuration produced high porosity granules with broad bimodal size distributions, especially in the $16 \mathrm{~mm}$ and $24 \mathrm{~mm}$ TSGs. Three dimensionless numbers, Froude number $(F r)$, liquid-to-solid ratio $(L S R)$, and powder feed number $(P F N)$, were identified and their effect on granule size distribution, porosity and liquid distribution tested. Granule size significantly increased with increasing LSR as expected. However, $F r$ and $P F N$ had no statistically significant effect on $\mathrm{d}_{10}$ or $\mathrm{d}_{50}$ and only a small effect on $\mathrm{d}_{90}$. In contrast, granulator scale had a strong effect on granule size distribution, with $\mathrm{d}_{90}$ increasing almost linearly with barrel diameter. This is consistent with breakage of large granules being a dominant mechanism and directly controlled by the geometry of the screw. As $F r$ and $P F N$ had little effect on granule properties, production rate can be increased by "scaling out", i.e. increasing both screw speed and powder feed rate, provided LSR is kept constant. However, scaling up the process to larger barrel diameters will cause an increase in granule size.

30 This DFS screw configuration produced porous granules $(0.5<\varepsilon<0.6)$. Granule porosity decreased with increasing $L S R$, but was insensitive to granulator scale, $P F N$ and $F r$. Thus, scaling up the twin screw granulation process while keeping granule porosity constant is relatively easy. Liquid distribution was relatively poor with this screw configuration, but insensitive to granulator scale.

35 Keywords: twin screw granulation, continuous manufacturing, powders, scaling

*Corresponding author

Phone: +44 1142227592

Email: james.litster@sheffield.ac.uk 


\section{Introduction}

Powder processing is critical in many industries including catalysts, pharmaceuticals, agrochemicals and minerals. In the pharmaceutical industry more than $75 \%$ of the final products are in solid dosage forms [1]. The high quality required in pharmaceutical products calls for the understanding of their manufacturing processes and their impact on intermediate and final product properties [2]. In the past several years, there have been advances in process understanding, along with the expansion of continuous manufacturing, in the pharmaceutical industry driven by several initiatives by regulatory agencies and pharmaceutical companies [3], [4].

There are three common manufacturing routes for pharmaceutical solid dosage forms - direct compression, dry granulation and wet granulation. For continuous wet granulation, twin screw wet granulation (TSG) has emerged as an alternative to batch granulation. In general, some of the advantages of continuous processing over batch processing include reduced equipment size, reduced development time using a smaller amount of the active pharmaceutical ingredient, increased controllability and ability to integrate process analytical tools [5], [6]. In comparison to batch granulation, TSG provides the optimum throughput necessary in pharmaceutical manufacturing, is flexible in design and has been shown to have regime-separated granulation rate processes, i.e. wetting and nucleation, breakage and attrition, and layering and consolidation, along the length of the TSG [7], [8].

One of the advantages of continuous processing as a whole is that it might require limited scale-up since the amount of processed material can be increased by simply augmenting the total throughput (powder flow rate) and/or extending the processing time at one scale. While this is true, the reality is that different scales of continuous processing equipment exist and are needed. Different equipment scales are used depending on total throughput of the processed material as well as the stage of development: early development, clinical trials or manufacturing. While several researchers have studied the influence of TSG process parameters (powder flow rate, liquid flow rate and screw speed) on granule properties (size distribution, shape, porosity and strength), their findings are applicable only to the equipment scale on which the experiments were conducted. This could potentially lead to difficulties during scale up if the granule attributes are not preserved [9], [10]. Djuric et al. compared two twin screw granulator scales (19 $\mathrm{mm}$ and $27 \mathrm{~mm}$ ) using a full factorial design by varying the total powder flow rate and screw rotation rate. Although these studies considered the Froude number and the screw speed, neither parameter was held constant 
during scale up [11]. Nevertheless, the main results showed that a higher percentage of fines (granules $<125 \mu \mathrm{m}$ ) was obtained in the smaller granulator $(\mathrm{D}=19 \mathrm{~mm}$ ) while a higher percentage of over-sized granules $(>3150 \mu \mathrm{m})$ was obtained in the larger granulator $(\mathrm{D}=27 \mathrm{~mm})$. To the best of our knowledge, this is the only published work comparing different TSG scales.

5 In addition, the powder flow rate, often used as a scaling parameter, has been shown to have an influence on granule attributes [12]. The powder flow rate largely determines the fill level of the powder inside the TSG barrel. Higher powder flow rates lead to greater compaction and densification of the powder in the TSG barrel, affecting the size, shape, strength and porosity of the granules. Djuric et al. showed that the median granule size $\left(\mathrm{d}_{50}\right)$ increased with increasing total powder flow rate, especially for the larger granulator. In a different study, Dhenge et al. found the effect of flow rate to be the opposite, where the granule size decreased with increasing flow rate [10]. The differences in results could be due to the different screw configurations used in the studies. On the other hand, several studies have shown the screw speed to have only minor effects on the granule properties [12], [13].

One of the advantages of TSG is the flexibility in design, including a wide range of possible screw elements and screw configurations to be used. Most screw elements and configurations used in TSG have been adopted from hot melt extrusion, which was the original purpose of a twin screw machine. With this in mind, the effects of screw elements (conveying elements, kneading elements, distributive mixing elements, and distributive feed screw) and screw configurations on granule properties have been studied by several researchers. Conveying elements (CEs) have been shown to yield bi-modal granule size distributions and highly porous granules [8], [14], [15]. Kneading elements (KEs), depending on their orientation, can behave similarly to CEs (offset angles of $30^{\circ}$ and $60^{\circ}$ in the forward direction), or very differently (offset angle of $90^{\circ}$ ) by forcing the material against the direction of the flow leading to less fines in the granulation as well as highly dense, elongated-shaped granules [7], [16], [17]. Distributive mixing elements (DMEs) were shown to yield highly porous granules and mono-modal granule size distributions with a large fraction of the granules between 100 to $1000 \mu \mathrm{m}$ [18]. The distributive feed screw (DFS) has been studied relatively less than other screw elements [8]. We recently reported the effect of DFS on granule properties in an 11-mm TSG [16]. The DFS behave similarly to CEs, yielding bimodal granule size distributions and highly porous granules at the process parameters used. The DFS had not been characterized for the $16 \mathrm{~mm}$ and $24 \mathrm{~mm}$ TSGs used in these studies. 
The main objective of this work is to identify key dimensionless groups that control granule properties and develop a model to map the operating space of three geometrically similar granulator scales: $11 \mathrm{~mm}, 16 \mathrm{~mm}$, and $24 \mathrm{~mm}$ diameter twin screw granulators. While the process parameters themselves are scale dependent, these dimensionless groups are scale independent.

5 Consequently, three dimensionless groups for scaling were identified and tested. These were the liquid to solid ratio $(L S R)$, Froude number $(F r)$, and the powder feed number $(P F N)$. A distributive feed screw (DFS), otherwise known as combing elements [8], was used as part of the screw configuration in all three TSG scales. Granulation properties, namely granule size distribution (GSD) and metrics $\left(d_{10}, d_{50}\right.$, and $\left.d_{90}\right)$, granule porosity, and liquid distribution as a function of scaling (process) parameters were compared for all three TSG scales in this study.

2. Developing potential scaling rules using dimensional analysis

Consider the process parameters that are available to us to vary when scaling a twin screw process: $D, \omega, L, g, \dot{m}_{p}, \dot{m}_{l}, \rho_{b}, F_{1}, F_{2}, \ldots$, where $D$ is the barrel diameter, $\omega$ is the angular velocity 15 of the shaft, $L$ is the barrel length, $\dot{m}_{p}$ and $\dot{m}_{l}$ are the mass flow rates of the powder and liquid respectively, $\rho_{b}$ is the bulk density of the powder and $F_{1}, F_{2}, \ldots$ are a series of geometric ratios that describe the geometry of the individual screw elements and the screw configuration.

The granule attributes of interest are parameters of the granule size distribution $\left(d_{10}, d_{50}, d_{90}\right.$, etc.), the granule porosity $(\varepsilon)$ and the liquid distribution $(L D)$. In general, we can write:

$d_{50}=f_{1}\left(D, \omega, L, g, \dot{m}_{p}, \dot{m}_{l}, \rho_{b}, F_{1}, F_{2}, \ldots\right)$

$\varepsilon=f_{2}\left(D, \omega, L, g, \dot{m}_{p}, \dot{m}_{l}, \rho_{b}, F_{1}, F_{2}, \ldots\right)$

and so on. Applying the principles of dimensional analysis, we can reframe these functions in terms of controlling dimensionless groups:

$\frac{d_{50}}{D}=g_{1}\left(L S R, P F N, F r, \frac{L}{D}, F_{1}, F_{2}, \ldots\right)$

$25 \varepsilon=g_{2}\left(L S R, P F N, F r, \frac{L}{D}, F_{1}, F_{2}, \ldots\right)$

where $L S R$ is the liquid to solid ratio:

$L S R=\frac{\dot{m}_{l}}{\dot{m}_{p}}$

$P F N$ is the powder feed number: 
$P F N=\frac{\dot{m}_{p}}{\rho_{b} \omega D^{3}}$

and $F r$ is the Froude number:

$F r=\frac{D \omega^{2}}{2 g}$

Note that we have neglected formulation properties in this analysis on the assumption that these

5 will not be changed during scale up. Further, if we undertake our scale up keeping the TSGs geometrically similar, eqns. 3 and 4 can be simplified to:

$d_{50}=D \cdot g_{1}(L S R, P F N, F r)$

$\varepsilon=g_{2}(L S R, P F N, F r)$

Note that this analysis suggests that parameters of the particle size distribution may be a 10 function of scale (TSG barrel diameter) as well as LSR, PFN and Fr. While this analysis is performed purely on the basis of dimensional analysis, we can look at the physical significance of the different dimensionless groups. The liquid to solid ratio $(L S R)$ is always a critical parameter in wet granulation. At low $L S R$, the granule size distribution is developed through a combination of nucleation, breakage and powder layering with the fines to lump ratio directly related to $L S R$. At higher LSR, coalescence and extruded granules are observed [19], [20].

The powder feed number $(P F N)$ is proportional to the ratio of volumetric feed rate to the turnover of volume in the shaft due to the screw rotation. It is therefore related to the fill level in a particular screw element. For any element, the rate of volume turnover is:

$\dot{V}=F_{1} D^{2}\left(\frac{\omega}{2 \pi}\right) L_{e l e m}$

20 where $L_{\text {elem }}$ is the length an element pushes material forward during one screw rotation, and $F_{1}$ is a geometric ratio related to the fraction of free cross sectional area of the barrel after accounting for the shaft and screw element:

$F_{1}=\frac{A_{\text {elem }}}{D^{2}}$

The length to diameter ratio of an element is also a known geometric ratio:

$25 \quad F_{2}=\frac{L_{\text {elem }}}{D}$

The net forward velocity of powder $\left(v_{p}\right)$ will be lower than the screw flight due to slip of the powder against the screw element surface as well as back mixing. We define: 
$F_{3}=\frac{2 \pi v_{p}}{\omega L_{\text {elem }}}$

Thus the fractional fill level in a screw element is:

$\phi=\frac{\dot{m}_{p} / \rho_{b}}{F_{1} F_{2} F_{3} \omega D^{3}}=\frac{1}{F_{1} F_{2} F_{3}} P F N$

5 For example, for the simple conveying elements used in this study, $F_{1}=0.45$ and $F_{2}=1$. If we estimate $F_{3}=0.5$, for the center point conditions used in this paper, $P F N=0.0130$ and $\phi \approx 0.36$. Note that $F_{3}$ may vary with powder flow rate and therefore $P F N$. If $F_{3}$ is independent of $P F N$ it implies that powder residence time is independent of flow rate.

The Froude number $(F r)$ is important for high shear mixer granulators where the balance between gravity and centripetal force establishes the flow field in the granulator. It is unclear whether $\mathrm{Fr}$ will have a significant effect on powder flow in the confined barrel of the TSG.

3. Materials and Methods

\subsection{Materials and Equipment}

A placebo formulation composed of $\alpha$-lactose monohydrate $(73.5 \% \mathrm{w} / \mathrm{w})$, microcrystalline cellulose $(20 \% \mathrm{w} / \mathrm{w})$, hydroxypropylmethyl cellulose $(5 \% \mathrm{w} / \mathrm{w})$ and croscarmellose sodium (1.5\% $\mathrm{w} / \mathrm{w}$ ) was used in this study. This is the same formulation used in studies of rate processes in the $16 \mathrm{~mm}$ twin screw granulator [17], [18]. Size parameters of the blend components and blend are given in Table 1. For the 11-mm TSG experiments, the dry blend was pre-mixed using a Turbula ${ }^{\circledR}$ T2F mixer (Glen Mills Inc., New Jersey, USA) in batches of $500 \mathrm{~g}$ for 20 minutes at 46 RPM. For the 16mm TSG experiments, a Plough mixer (Processall Inc., Cincinnati, OH, USA) was used to blend the dry materials in batches of $1000 \mathrm{~g}$ for 5 minutes at the impeller speed of $200 \mathrm{RPM}$. For the 24mm TSG experiments, a 30-L BV030 tote blender (Pharmatech, Warwickshire, UK) was used to pre-mix the dry formulation in batches of $8000 \mathrm{~g}$ for 15 minutes at 12 RPM.

25 The pre-mixed formulation was fed into twin screw granulators (TSG) of three different sizes. These were the Pharma 11-mm (40:1 L:D), EuroLab 16mm TSG (25:1 L:D), and Pharma 24mm (40:1 L:D) twin screw granulators (Thermo Fisher Scientific, Karlsruhe, Germany). Pictures of the distributive feed screw (DFS) and the screw configuration used in these experiments are shown in Figure 1. 
A Brabender DDSR20 volumetric feeder (Brabender-Technologie, Germany) was used for the 11-mm TSG experiments. A gravimetric calibration for the placebo blend used was created yielding a linear correlation $\left(\mathrm{R}^{2}=0.9997\right)$ between the powder mass flow rate and the controller input. Gravimetric Brabender feeders, FW18 and FW40, were used to feed the formulation into

5 the $16 \mathrm{~mm}$ and $24 \mathrm{~mm}$ TSGs, respectively. The granulating liquid was composed of $0.1 \%(\mathrm{w} / \mathrm{w})$ aqueous solution of nigrosin black dye. Granulation liquid was fed into the granulators at different feed rates to achieve liquid to solid ratios $(L S R)$ of $0.15,0.20,0.25$ and 0.30 . For the $11 \mathrm{~mm}$ (Thermo Fisher Scientific, Karlsruhe, Germany) and 16mm (Cole Parmer, Vernon Hills, IL, USA) TSGs, peristaltic pumps were used. For the $24 \mathrm{~mm}$ TSG, a loss-in-weight Thermo liquid feeder with a Watson Marlow pump head (Wilmington, MA, USA) was used. For the $24 \mathrm{~mm}$ TSG, the liquid feed stream coming from the pump is split into two streams after it reaches the inlet port in the TSG. This is different in the $11 \mathrm{~mm}$ and $16 \mathrm{~mm} \mathrm{TSG}$, where only one liquid stream is fed into the granulators.

The powder was fed into the third to last zone and the liquid was fed into the second to last zone of each TSG. Figure 2 shows the inlet positions of the powder feed (Zone 3) and liquid feed (Zone 2). Three conveying elements (CEs) were placed downstream of the DFS used and before the TSG outlet. The $11 \mathrm{~mm}$ and $24 \mathrm{~mm}$ TSGs have 8 zones, while the $16 \mathrm{~mm}$ TSG has only 6 zones. The $11 \mathrm{~mm}$ and $24 \mathrm{~mm}$ TSGs are geometrically identical to each other having an L:D of 40:1, while the $16 \mathrm{~mm}$ TSG has an L:D of 25:1. This means that the powder will go through 1.5 CEs more in the $11 \mathrm{~mm}$ and $24 \mathrm{~mm}$ TSG than in the $16 \mathrm{~mm}$ TSG after liquid addition before reaching the DFS.

The process parameters in all three twin screw granulators were based on the three dimensionless groups defined in equations 5-7. Four $L S R$ values $(0.15,0.20,0.25$, and 0.30$)$, three $F r$ values $(1.43,3.22$, and 5.73$)$ and three $P F N$ values $\left(7.77 \times 10^{-3}, 1.30 \times 10^{-2}\right.$, and $\left.1.81 \times 10^{-2}\right)$ were studied. The $L S R$ values were chosen based on results from previous studies in the $16 \mathrm{~mm}$ TSG.

25 These studies showed that the granule properties were most sensitive using these LSR values [17], [21]. In addition, the $F r$ and $P F N$ values were calculated based on the standard operating conditions for the $16 \mathrm{~mm}$ TSG. Typical rotation rates and powder flow rates in the $16 \mathrm{~mm}$ TSG are 200-800 RPM and 1-12 kg/hr, respectively. A full factorial experimental design was used. The screw rotation rates and powder flow rates used for each TSG scale are summarized in Table 2. 
Due to equipment limitations, some experiments in the $16 \mathrm{~mm} \mathrm{TSG}$, indicated by N/A, were not completed.

\subsection{Granule characterization}

Granules collected for each experiment were spread on a tray and dried at room temperature for 48 hours. The dry granules were split using a rotary cone sample divider (Laborette 27, Fritsch $\mathrm{GmbH}$, Idar-Oberstein, Germany). The granule size distribution (GSD) was measured by sieve analysis using sieves from $63 \mu \mathrm{m}$ to $8 \mathrm{~mm}$ following a $\sqrt{ } 2$ series. The normalized mass frequency with respect to the logarithm of the particle size was plotted as shown in equation 13 [22].

$f_{i}(\ln x)=\frac{y_{i}}{\ln \left({ }^{x_{i}} / x_{i-1}\right)}$

where $y_{i}$ is the mass fraction in size interval $i$ and $x_{i}$ is the upper limit of the size interval $i$.

The true density of the granules was first measured using a helium pycnometer (AccuPyc, Micromeritics, Germany), followed by envelope density measurement using a Geopyc (Micromeritics, Germany). Granules in the size fraction 1.0-1.4 mm were used for all granule density measurements. The granule porosity $(\varepsilon)$ was then calculated using equation 14 .

$\varepsilon=1-\frac{\rho_{g}}{\rho_{s}}$

where $\rho_{g}$ and $\rho_{s}$ are the envelope and true density of the granules, respectively.

The method used in analyzing the liquid distribution $(L D)$ has been reported in El Hagrasy and Litster [17]. In brief, granule samples from each sieve fraction were dissolved in water, sonicated for one hour, followed by further dilution and centrifugation. The concentration of nigrosin dye in the supernatant was measured using UV/Vis spectrophotometry at $\lambda=574 \mathrm{~nm}$.

\section{Results and Discussion}

The main effects of scaling (processing) parameters (LSR, Fr and PFN) and TSG scale on granule size distributions (GSDs), granule size parameters $\left(d_{10}, d_{50}\right.$ and $\left.d_{90}\right)$, granule porosity $(\varepsilon)$ and liquid distribution $(L D)$ are presented and discussed for selected experiments in this section. Selected combinations of $L S R$ values, $F r$ values and $P F N$ values were chosen to demonstrate the overall behavior. In addition, the main effects of the parameters on the granule size metrics $\left(d_{10}\right.$, $d_{50}$ and $d_{90}$ ) over the full range of conditions studied are summarized. 


\subsection{Granule Size Distribution}

GSDs obtained from the $16 \mathrm{~mm}$ twin screw granulator (TSG) for $F r=3.22$ and $P F N=1.30 \times 10^{-}$

2 as a function of $L S R$ are shown in Figure 3. The granule size increased with increasing $L S R$. Bimodal GSDs were obtained in most cases using the distributive feed screw (DFS) configuration, especially at low values of $L S R$. Larger lumps leading to more and larger granules $(\geq 1 \mathrm{~mm})$ were obtained at high values of $L S R$. Hence, as the $L S R$ increased, the amount of fines $(<125 \mu \mathrm{m})$ decreased significantly with minor changes in the fraction of intermediate size granules $(>125 \mu \mathrm{m}$ $\&<1 \mathrm{~mm})$. Therefore, the major granulation rate processes for the DFS configuration were drop nucleation and layering of fines with limited breakage of lumps. This behavior was seen for all values of $F r$ and PFN studied. Although high values of $L S R$ yielded monomodal GSDs, most of the granules are too large for downstream pharmaceutical processing. For most processing conditions, the largest sized granules were less than $3000 \mu \mathrm{m}$ in size indicating breakage of larger lumps, which is consistent with findings of El Hagrasy and Sayin using different screw configurations in the same TSG scale [17], [18].

The effect of $F r$ on GSD at $P F N=1.30 \times 10^{-2}$ and $L S R$ values of 0.20 and 0.30 in the $16 \mathrm{~mm}$ TSG are plotted in Figure 4. Varying Fr did not have a significant effect on GSD. These results are consistent for all values of $P F N$ and $L S R$ used at all scales. GSDs for all three values of $P F N$ used at $F r=3.22$ and $L S R$ values of 0.20 and 0.30 in the $16 \mathrm{~mm}$ TSG are shown in Figure 5. There are only small differences in GSD caused by variations in the PFN when using the DFS configuration. These results are consistent for all values of Fr, LSR and TSG scales used. Minor changes in GSD indicate there may be slightly more breakage of large lumps at low Fr and low PFN, leading to more layering and reduction in fines.

The effect of TSG scale (or screw diameter - $D$ ) was analyzed and is summarized in Figure 6, which shows the results for $F r=3.22$ at $P F N=1.30 \times 10^{-2}$ at $L S R$ values of 0.20 and 0.30 . Bimodal

25 GSDs were common from the $16 \mathrm{~mm}$ and $24 \mathrm{~mm}$ TSGs, especially at low values of LSR. Nearly monomodal distributions were obtained for the $11 \mathrm{~mm}$ TSG. Better, more uniform GSDs were achieved for the $11 \mathrm{~mm}$ TSG with less large granules than in the other two TSG scales. Overall, more large granules were obtained for the $24 \mathrm{~mm}$ TSG than for the $16 \mathrm{~mm}$ TSG. In most cases, a larger fraction of fines was generated in the $16 \mathrm{~mm}$ than in the $24 \mathrm{~mm}$ TSG. Results suggest that breakage of large granules and lumps is dependent on geometry of the screw elements. As scale 
increases, the size of a granule that can leave the granulator without breaking also increases. Note, however, that the granulating liquid is fed into the $24 \mathrm{~mm}$ TSG differently than for the two smaller scales. The liquid feed is split into two streams, each on top of each screw, in the $24 \mathrm{~mm}$ TSG. This may have a confounding effect on the results.

The granule size parameters $\mathrm{d}_{10}, \mathrm{~d}_{50}$, and $\mathrm{d}_{90}$ are plotted as a function of $L S R, F r$ and $P F N$ in Figure 7 and 8. As expected, $\mathrm{d}_{10}, \mathrm{~d}_{50}$, and $\mathrm{d}_{90}$ increase with increasing LSR [17], [18]. However, Figure 7 shows that Fr only had a small effect on any of the GSD properties when compared to the effect of $L S R$. This was true for all other combination of parameters used. This is consistent with the limited studies on the literature which showed rotation rate did not have large effects on the granule properties [12], [13]. Nevertheless, $d_{90}$ increased with increasing $F r$ especially at high values of $L S R$. Figure 8 shows the effect of $P F N$ on GSD properties. Although, there is no significant impact of $P F N$ on $\mathrm{d}_{10}$ and $\mathrm{d}_{50}, \mathrm{~d}_{90}$ does increase with increasing $P F N$. Thus, increasing $F r$ and $P F N$ leads to slightly broader GSDs.

The effect of TSG scale on $\mathrm{d}_{10}, \mathrm{~d}_{50}$, and $\mathrm{d}_{90}$ as a function of $L S R$ is shown in Figure 9. The mean values of $\mathrm{d}_{10}, \mathrm{~d}_{50}$, and $\mathrm{d}_{90}$ were calculated from the results of the three $F r$ values for $P F N=1.30 \times 10^{-2}$. The TSG barrel diameter has a dramatic impact on the size of large granules (lumps) in the product. d90 increases approximately linearly with scale, with $d_{50}$ also increasing monotonically as scale increases. The effect of TSG scale on $d_{90}$ was greater than the effect of $L S R$. This is likely due to more efficient breakage at the $11 \mathrm{~mm}$ scale and supports the hypothesis that breakage is controlled by the geometry in the confined twin screw. For geometrically similar screw elements, the size of gap through which a granule can flow without breakage scales directly with the barrel diameter. There is not as clear a trend for $d_{10}$ with TSG scale. While $\mathrm{d}_{10}$ is greater for the $24 \mathrm{~mm}$ TSG, values for the $11 \mathrm{~mm}$ and the $16 \mathrm{~mm}$ TSGs are similar with the $11 \mathrm{~mm}$ TSG giving slightly higher $\mathrm{d}_{10}$ values. This probably reflects a complex balance between generation of

25 fines by breakage and/or attrition and layering of fines onto wet granule surfaces.

Statistical analysis was performed to elucidate the main effects, interactions, and levels of significance of the scaling (processing) parameters on the particle size. A summary of analysis of variance (ANOVA) showing the p-values for the full data set for the effect of TSG scale, $L S R$, $P F N$, and $F r$ on $\mathrm{d}_{10}, \mathrm{~d}_{50}$, and $\mathrm{d}_{90}$ are given in Table 3 . At $p=0.05$, only TSG scale (barrel diameter) and $L S R$ have a statistically significant effect on $d_{10}$ and $d_{50}$. All four parameters do have a 
statistically significant effect on $d_{90}$. However, the main effects plot (Figure 10) shows that the impact of scale and $L S R$ on $\mathrm{d}_{90}$ is much greater than that of either PFN or Fr. For d90, two of the interactions, $T S G^{*} L S R$ and $T S G^{*} P F N$ are also significant. The coarse end to the GSD is much more sensitive to changes in operating conditions than the fines.

4.2. Granule Porosity and Liquid Distribution

The porosity of granules with size between $1.0 \mathrm{~mm}$ and $1.4 \mathrm{~mm}$ was measured. The granule porosity as a function of $L S R$, TSG scale $F R$ and $P F N$ is shown in Figure 11 and statistical analysis is shown in Table 4. Granule porosity decreases with increasing LSR. In all cases this change was statistically significant ( $p$-value $<0.05$ ). The TSG scale, $F r$ and $P F N$ did not generate a clear trend in the measured porosity. Note that granule porosity for the DFS configuration was always high, in the range of $50-60 \%$.

Due to the time consuming nature of the analysis, liquid distribution was only measured at $L S R$ $=0.15$ (where liquid distribution is expected to be the poorest) and at $F r=5.73$ and $P F N=7.77 \times 10^{-}$ ${ }^{3}$. Liquid distribution results are presented in Figure 12 for the three TSG scales. The similar slopes of the distributions suggest that there is no significant effect of TSG scale on the efficiency of mixing and liquid distribution.

\subsection{Implications for TSG Design and Scaling}

The DFS configuration was chosen for this scaling study because it was of industrial interest, the screw designs were available at all three TSG scales we used, and there was relatively little published data on this configuration. This configuration yields bimodal size distributions with relatively poor liquid distributions, especially at $16 \mathrm{~mm}$ and $24 \mathrm{~mm}$ barrel diameters. Previous studies have shown that efficient breakage of large granules (lumps) formed in the liquid addition section is a key to achieving monomodal size distribution and good liquid distribution [17], [18]. The DFS elements look superficially similar to Distributed Mixing Elements (DMEs) which give efficient breakage of large granules. However, the DFS elements are cut out conveying elements with the same spiral configuration as conveying elements. Thus, relatively large lumps can be conveyed along the barrel without being broken by the DFS. A combination of DFS and CE, as we have used, is not likely to be the optimum configuration for controlling granule size distribution. On the other hand, like DME configurations, the DFS configuration does produce 
consistently high porosity (low density) granules which could be an advantage for downstream compressibility of the granules to form tablets.

With regard to developing simple and reliable scaling rules, this study is a "good news, bad news" story. First the good news: A striking feature of this study is how little effect the basic process parameters, powder flow rate and screw speed, and their dimensionless counterparts $P F N$ and $\mathrm{Fr}$, have on the granule properties, indicating the robust nature of TSG. Contrast this with previous studies, which have shown that the screw configuration (type and arrangement of screw elements) has a very large impact on granule properties [15]-[18]. Thus, a very wide range of production rates can be achieved with relatively little effect on granule properties through scaling out, i.e., operating the same TSG for longer campaign times, and at increased screw speed and powder feed rate. To increase production rate from the same screw, we recommend increasing the screw speed to maintain $P F N$ constant, although moderate changes in $P F N$ are also likely to be acceptable. $L S R$ should be kept constant in design by increasing the liquid feed in proportion to the powder feed and then used as a fine tuning parameter during operation. This scaling out approach means that the same granulator may possibly be used for all phases of clinical trials and even in full scale production for some pharmaceutical products.

In contrast, scaling up by changing the barrel diameter does have a strong impact on the size of large granules and the spread of the granule size distribution. This is consistent with breakage (the dominant rate process) being controlled by geometry of the TSG. To traverse the TSG, unbroken, weak granules must be small enough to pass through gaps between elements that intermesh on the two shafts. For geometrically similar screw elements, these gaps will increase linearly with barrel diameter and the size of the lumps ( $\left.\mathrm{d}_{90}\right)$ will also increase approximately linearly. This increase is predictable using an appropriate mechanistically based model of the TSG, but is unavoidable. It is not possible to achieve the same GSD in the large scale TSG as in the small scale if the granulators are geometrically similar, and this will have implications for downstream drying, milling and tableting. It may be possible to redesign the key screw element, DFS in this case, so that the absolute gap size remains invariant during scale up. This would improve our ability to scale up the process without changing the granule size distribution, as well as other granule attributes. 
Sometimes granule porosity (density), rather than granule size, may be the key property of interest. Here, the news is better. The granule porosity is insensitive to most process changes except $L S R$ and is also scale independent. In the TSG, granules undergo relatively little densification, particularly for this screw configuration. Granule density will change little when either scaling out or up. Contrast this with high shear wet granulation (HSWG), where granule densification coupled with coalescence can dominate the granule properties. It is very difficult to scale HSWG and maintain constant granule porosity.

\section{Conclusions}

Three dimensionless groups for scaling were identified and tested: the liquid to solid ratio $(L S R)$, Froude number $(F r)$ and the powder feed number $(P F N)$. These dimensionless groups were studied in three different geometrically-similar TSG scales $(11 \mathrm{~mm}, 16 \mathrm{~mm}$ and $24 \mathrm{~mm})$ using a distributive feed screw (DFS) as part of the screw configuration. The DFS configuration yielded bimodal granule size distributions (GSDs) with poor liquid distribution. GSDs and metrics were strongly dependent on $L S R$. The granule size increased with increasing $L S R$. However, $F r$ and $P F N$ had only a minor, but statistically significant, effect on the larger lumps ( $\left.d_{90}\right)$ of GSDs with no significant effect on $\mathrm{d}_{10}$ or $\mathrm{d}_{50}$. In contrast, $\mathrm{d}_{90}$ was strongly dependent on TSG scale with the size of lumps increasing approximately linearly with barrel diameter. More efficient breakage of large lumps occurred with decreasing TSG scale. This fits with our mechanistic understanding that with

20 the current liquid feeding method, breakage is the most important rate process, determining the final properties of granules, and the size of granules broken is set by geometry (i.e. gap size). Gap size is proportional to scale (screw diameter). Nevertheless, the TSG scale did not have an effect on the granule porosity for the DFS configuration.

When operating at one scale, but increasing the powder flow rate, we recommend increasing the liquid flowrate to maintain $L S R$ constant and increasing the screw speed to keep PFN constant. This strategy was effective for DFS elements over all conditions studied. When increasing TSG scale, expect more and larger lumps to be produced. Reducing $L S R$ reduces the amount of lumps. However, do not expect to exactly match the GSD by this strategy. In general, as scale increases, the GSD is broader and more likely to be bimodal. 


\section{Acknowledgements}

The authors would like to acknowledge Vertex, Eli Lilly and Glaxo-Smith-Kline (GSK) for financial support for this research work. Special mention to Dr. Vicky He (GSK) for hosting us and helping us in performing the $24 \mathrm{~mm}$ TSG experiments at one of the GSK facilities.

\section{References}

[1] R. I. . Mahato and A. S. . Narang, "Tablets," in Pharmaceutical Dosage Forms and Drug Delivery, Second Edition, CRC Press, 2011, pp. 313-336.

[2] H. Wu, M. Tawakkul, M. White, and M. A. Khan, "Quality-by-Design (QbD): An integrated multivariate approach for the component quantification in powder blends," Int. J. Pharm., vol. 372, no. 1-2, pp. 39-48, May 2009.

[3] ICH, "Pharmaceutical Development - Q8 (R2),” 2009.

[4] FDA, "Guidance for Industry PAT - A Framework for Innovative Pharmaceutical Development, Manufacturing, and Quality Assurance," 2004.

[5] R. M. Dhenge, R. S. Fyles, J. J. Cartwright, D. G. Doughty, M. J. Hounslow, and A. D. Salman, "Twin screw wet granulation: Granule properties," Chem. Eng. J., vol. 164, no. 2-3, pp. 322-329, Nov. 2010.

[6] C. Vervaet and J. P. Remon, "Continuous granulation in the pharmaceutical industry," Chem. Eng. Sci., vol. 60, no. 14, pp. 3949-3957, Jul. 2005.

[7] D. Djuric and P. Kleinebudde, "Continuous granulation with a twin-screw extruder: Impact of material throughput," Pharm. Dev. Technol., vol. 15, no. 5, pp. 518-525, 2010.

[8] D. Djuric and P. Kleinebudde, "Impact of screw elements on continuous granulation with a twin-screw extruder," J. Pharm. Sci., vol. 97, no. 11, pp. 4934-4942, 2008.

[9] J. Vercruysse, D. Córdoba Díaz, E. Peeters, M. Fonteyne, U. Delaet, I. Van Assche, T. De Beer, J. P. Remon, and C. Vervaet, "Continuous twin screw granulation: Influence of process variables on granule and tablet quality," Eur. J. Pharm. Biopharm., vol. 82, no. 1, pp. 205-211, Sep. 2012.

[10] R. M. Dhenge, J. J. Cartwright, D. G. Doughty, M. J. Hounslow, and A. D. Salman, “Twin screw wet granulation: Effect of powder feed rate," Adv. Powder Technol., vol. 22, no. 2, pp. 162-166, Mar. 2011.

[11] D. Djuric, B. Van Melkebeke, P. Kleinebudde, J. P. Remon, and C. Vervaet, "Comparison of two twin-screw extruders for continuous granulation,” Eur. J. Pharm. Biopharm., vol. 71, no. 1, pp. 155-160, Jan. 2009.

[12] T. C. Seem, N. A. Rowson, A. Ingram, Z. Huang, S. Yu, M. de Matas, I. Gabbott, and G. K. Reynolds, "Twin screw granulation - A literature review," Powder Technol., vol. 276, pp. 89-102, May 2015.

[13] M. R. Thompson, "Twin screw granulation - review of current progress," Drug Dev. Ind. Pharm., vol. 41, no. 8, pp. 1223-1231, Aug. 2015. 
[14] M. R. Thompson and J. Sun, "Wet granulation in a twin-screw extruder: Implications of screw design,” J. Pharm. Sci., vol. 99, no. 4, pp. 2090-2103, 2010.

[15] R. M. Dhenge, K. Washino, J. J. Cartwright, M. J. Hounslow, and A. D. Salman, "Twin screw granulation using conveying screws: Effects of viscosity of granulation liquids and flow of powders," Powder Technol., vol. 238, pp. 77-90, 2013.

[16] R. Sayin, L. Martinez-Marcos, J. G. Osorio, P. Cruise, I. Jones, G. W. Halbert, D. A. Lamprou, and J. D. Litster, "Investigation of an $11 \mathrm{~mm}$ diameter twin screw granulator: Screw element performance and in-line monitoring via image analysis," Int. J. Pharm.

[17] A. S. El Hagrasy and J. D. Litster, "Granulation rate processes in the kneading elements of a twin screw granulator," AIChE J., vol. 59, no. 11, pp. 4100-4115, 2013.

[18] R. Sayin, A. S. El Hagrasy, and J. D. Litster, "Distributive mixing elements: Towards improved granule attributes from a twin screw granulation process," Chem. Eng. Sci., vol. 125, pp. 165-175, Mar. 2015.

[19] M. Benali, V. Gerbaud, and M. Hemati, "Effect of operating conditions and physicochemical properties on the wet granulation kinetics in high shear mixer," Powder Technol., vol. 190, no. 1-2, pp. 160-169, 2009.

[20] S. Shanmugam, "Granulation techniques and technologies: recent progresses," Bioimpacts, vol. 5, no. 1, pp. 55-63, Feb. 2015.

[21] A. S. El Hagrasy, J. R. Hennenkamp, M. D. Burke, J. J. Cartwright, and J. D. Litster, "Twin screw wet granulation: Influence of formulation parameters on granule properties and growth behavior," Powder Technol., vol. 238, pp. 108-115, 2013.

[22] T. Allen, “4 - Particle size analysis by sieving,” T. B. T.-P. S. and P. S. D. Allen, Ed. Amsterdam: Elsevier, 2003, pp. 208-250.

Tables

\begin{tabular}{ccccc}
\hline Material & Grade & $\mathrm{d} 10(\mu \mathrm{m})$ & $\mathrm{d} 50(\mu \mathrm{m})$ & $\mathrm{d} 90(\mu \mathrm{m})$ \\
\hline$\alpha$-lactose monohydrate & Pharmatose 200M & 6.2 & 40.6 & 111.4 \\
Microcrystalline cellulose & Avicel PH101 & 20.9 & 51.8 & 107.2 \\
Hydroxypropylmethyl cellulose & Hypromellose & 34.2 & 83.5 & 165.4 \\
Croscarmellose sodium & Ac-Di-Sol & 18.3 & 44.6 & 116 \\
Initial blend & - & 54.4 & 88.4 & 122.8 \\
\hline
\end{tabular}

Table 1 - Particle size of raw materials 


\begin{tabular}{|c|c|c|c|c|}
\hline & $\boldsymbol{F r}$ & Rotation Rate $\left(\mathrm{min}^{-1}\right)$ & PFN & Flow Rate $\left(\mathrm{kg} \mathrm{hr}^{-1}\right)$ \\
\hline \multirow[t]{9}{*}{$\mathrm{D}=11 \mathrm{~mm}$} & \multirow[t]{3}{*}{1.43} & \multirow[t]{3}{*}{482} & 7.77E-03 & 0.94 \\
\hline & & & $1.30 \mathrm{E}-02$ & 1.57 \\
\hline & & & $1.81 \mathrm{E}-02$ & 2.19 \\
\hline & \multirow[t]{3}{*}{3.22} & \multirow[t]{3}{*}{723} & $7.77 \mathrm{E}-03$ & 1.41 \\
\hline & & & $1.30 \mathrm{E}-02$ & 2.35 \\
\hline & & & $1.81 \mathrm{E}-02$ & 3.29 \\
\hline & \multirow[t]{3}{*}{5.73} & \multirow[t]{3}{*}{964} & 7.77E-03 & 1.88 \\
\hline & & & $1.30 \mathrm{E}-02$ & 3.14 \\
\hline & & & $1.81 \mathrm{E}-02$ & 4.39 \\
\hline \multirow[t]{9}{*}{$D=16 \mathrm{~mm}$} & \multirow[t]{3}{*}{1.43} & \multirow[t]{3}{*}{400} & 7.77E-03 & 2.40 \\
\hline & & & $1.30 \mathrm{E}-02$ & 4.00 \\
\hline & & & $1.81 \mathrm{E}-02$ & 5.60 \\
\hline & \multirow[t]{3}{*}{3.22} & \multirow[t]{3}{*}{600} & 7.77E-03 & 3.60 \\
\hline & & & $1.30 \mathrm{E}-02$ & 6.00 \\
\hline & & & $1.81 \mathrm{E}-02$ & 8.40 \\
\hline & \multirow[t]{3}{*}{5.73} & \multirow[t]{3}{*}{800} & 7.77E-03 & 4.80 \\
\hline & & & $1.30 \mathrm{E}-02$ & 8.00 \\
\hline & & & $1.81 \mathrm{E}-02(\mathrm{~N} / \mathrm{A})$ & $11.20(\mathrm{~N} / \mathrm{A})$ \\
\hline \multirow[t]{9}{*}{$D=24 \mathrm{~mm}$} & \multirow[t]{3}{*}{1.43} & \multirow[t]{3}{*}{327} & 7.77E-03 & 6.61 \\
\hline & & & $1.30 \mathrm{E}-02$ & 11.02 \\
\hline & & & $1.81 \mathrm{E}-02$ & 15.43 \\
\hline & \multirow[t]{3}{*}{3.22} & \multirow[t]{3}{*}{490} & 7.77E-03 & 9.92 \\
\hline & & & $1.30 \mathrm{E}-02$ & 16.53 \\
\hline & & & $1.81 \mathrm{E}-02$ & 23.15 \\
\hline & \multirow[t]{3}{*}{5.73} & \multirow[t]{3}{*}{653} & 7.77E-03 & 13.23 \\
\hline & & & $1.30 \mathrm{E}-02$ & 22.05 \\
\hline & & & $1.81 \mathrm{E}-02$ & 30.86 \\
\hline
\end{tabular}

Table 2. Process parameters used for each TSG scale (D) based on dimensionless groups $F r$ and PFN 


\begin{tabular}{|c|c|c|c|}
\hline & $\mathrm{d}_{10}$ & $\mathrm{~d}_{50}$ & $\mathrm{~d}_{90}$ \\
\hline & \multicolumn{3}{|c|}{$p$-values } \\
\hline $\mathrm{TSG}$ & $\mathbf{0 . 0 0 0}$ & $\mathbf{0 . 0 0 0}$ & $\mathbf{0 . 0 0 0}$ \\
\hline$L S R$ & $\mathbf{0 . 0 0 0}$ & $\mathbf{0 . 0 0 0}$ & $\mathbf{0 . 0 0 0}$ \\
\hline$P F N$ & 0.898 & 0.652 & $\mathbf{0 . 0 0 0}$ \\
\hline$F r$ & 0.155 & 0.927 & $\mathbf{0 . 0 0 1}$ \\
\hline $\mathrm{TSG}^{*} L S R$ & 0.186 & $\mathbf{0 . 0 0 0}$ & $\mathbf{0 . 0 0 0}$ \\
\hline $\mathrm{TSG}^{*} P F N$ & 0.523 & 0.577 & $\mathbf{0 . 0 0 7}$ \\
\hline $\mathrm{TSG}^{*} F r$ & 0.085 & 0.608 & 0.127 \\
\hline$L S R^{*} P F N$ & 0.724 & 0.793 & 0.526 \\
\hline$L S R^{*} F r$ & 0.676 & 0.730 & 0.583 \\
\hline$P F N^{*} F r$ & 0.133 & 0.058 & $\mathbf{0 . 0 0 3}$ \\
\hline$R^{2} . R^{2}{ }_{a d j}$ & $72.13 \%, 54.32 \%$ & $96.47 \%, 94.21 \%$ & $97.14 \%, 95.31 \%$ \\
\hline
\end{tabular}

Table 3. Summary of statistical analysis showing the p-values from the analysis of variance (ANOVA) of $\mathrm{d}_{10}, \mathrm{~d}_{50}$ and $\mathrm{d}_{90}$ for all scaling parameters used and their second order interactions

\begin{tabular}{cc}
\cline { 2 - 2 } & $F r=3.22, P F N=1.30 \times 10^{-2}$ \\
& $p$-values \\
TSG & 0.003 \\
$L S R$ & 0.012 \\
$R^{2} . R^{2}{ }_{\text {adj }}$ & $91.00 \%, 83.50 \%$ \\
\hline & TSG $=16 \mathrm{~mm}, P F N=1.30 \times 10^{-2}$ \\
$F r$ & $p$-values \\
$L S R$ & 0.005 \\
$R^{2} . R^{2}{ }_{\text {adj }}$ & 0.041 \\
& TSG $=16 \mathrm{~mm}, \mathrm{mr}=3.22$ \\
$P F N$ & $p$-values \\
$L S R$ & 0.160 \\
$R^{2} . R^{2}{ }_{\text {adj }}$ & 0.010 \\
\hline
\end{tabular}

5 Table 4-Summary of statistical analysis on porosity showing the $p$-values as a function of scaling parameters for data in Figure 11. 


\section{Figures}

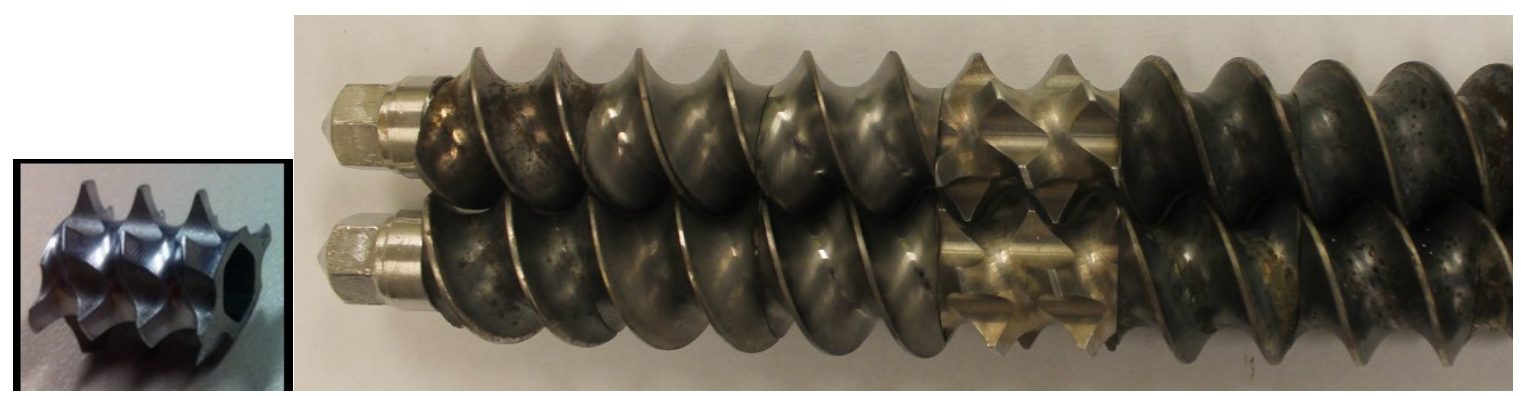

Figure 1 - Picture of (left) distributive feed screw (DFS) and (right) screw configuration used

\begin{tabular}{|c|c|c|c|c|c|c|c|}
\hline & $\begin{array}{l}\text { Liquid } \\
\text { Feed }\end{array}$ & $\begin{array}{c}\text { Powder } \\
\text { Feed }\end{array}$ & & $\begin{array}{c}\text { Mater } \\
\text { Dir }\end{array}$ & $\begin{array}{l}\text { Flow } \\
\text { on }\end{array}$ & & \\
\hline 40.1 & 40- & 4015 & 4an- & 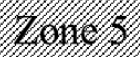 & 40 & 4.10 & 40 \\
\hline CE & DFS & \multicolumn{3}{|c|}{$\mathrm{CE}$} & \multicolumn{3}{|c|}{ Spacers } \\
\hline
\end{tabular}

Figure 2 - Schematic of screw configuration and powder and liquid inlet positions

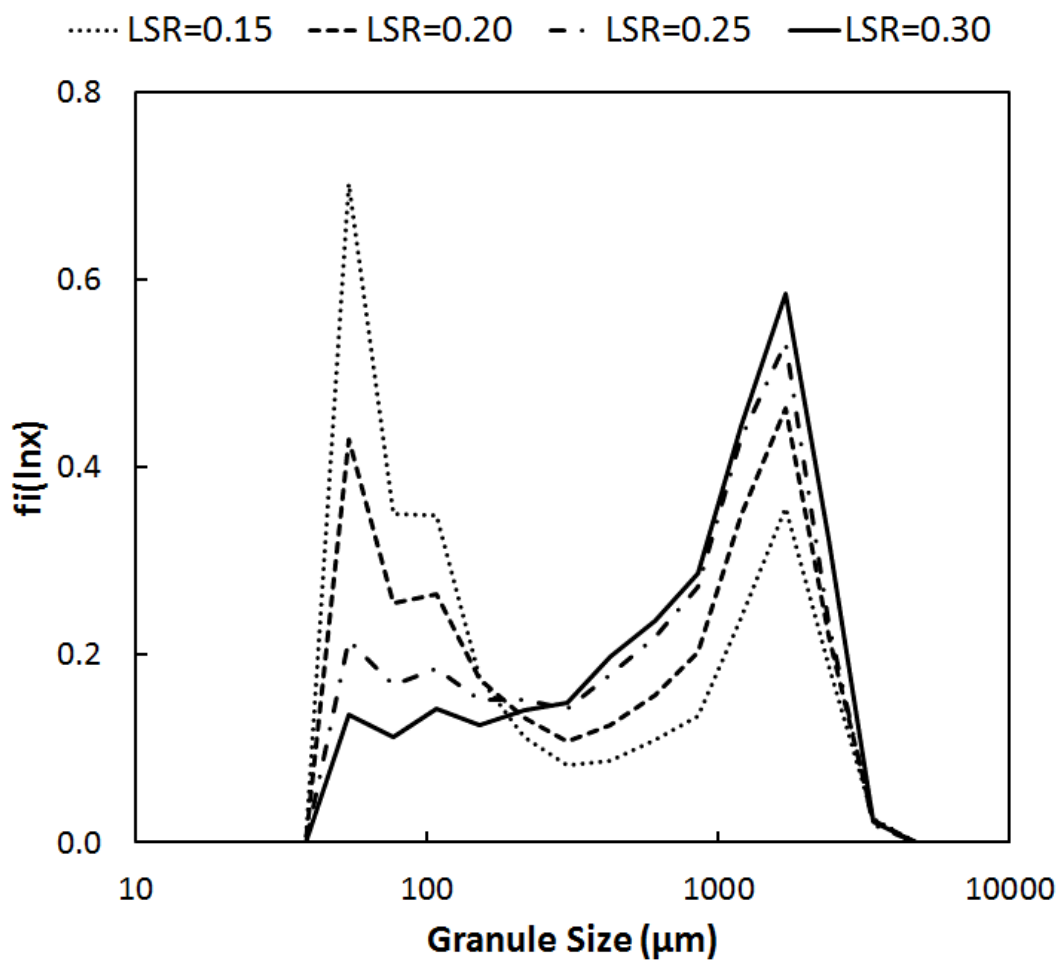

Figure 3 - Effect of $L S R$ on granule size distribution. Other parameters: $16 \mathrm{~mm}$ TSG, $F r=3.22$ and $P F N=1.30 \times 10^{-2}$ 
(A)

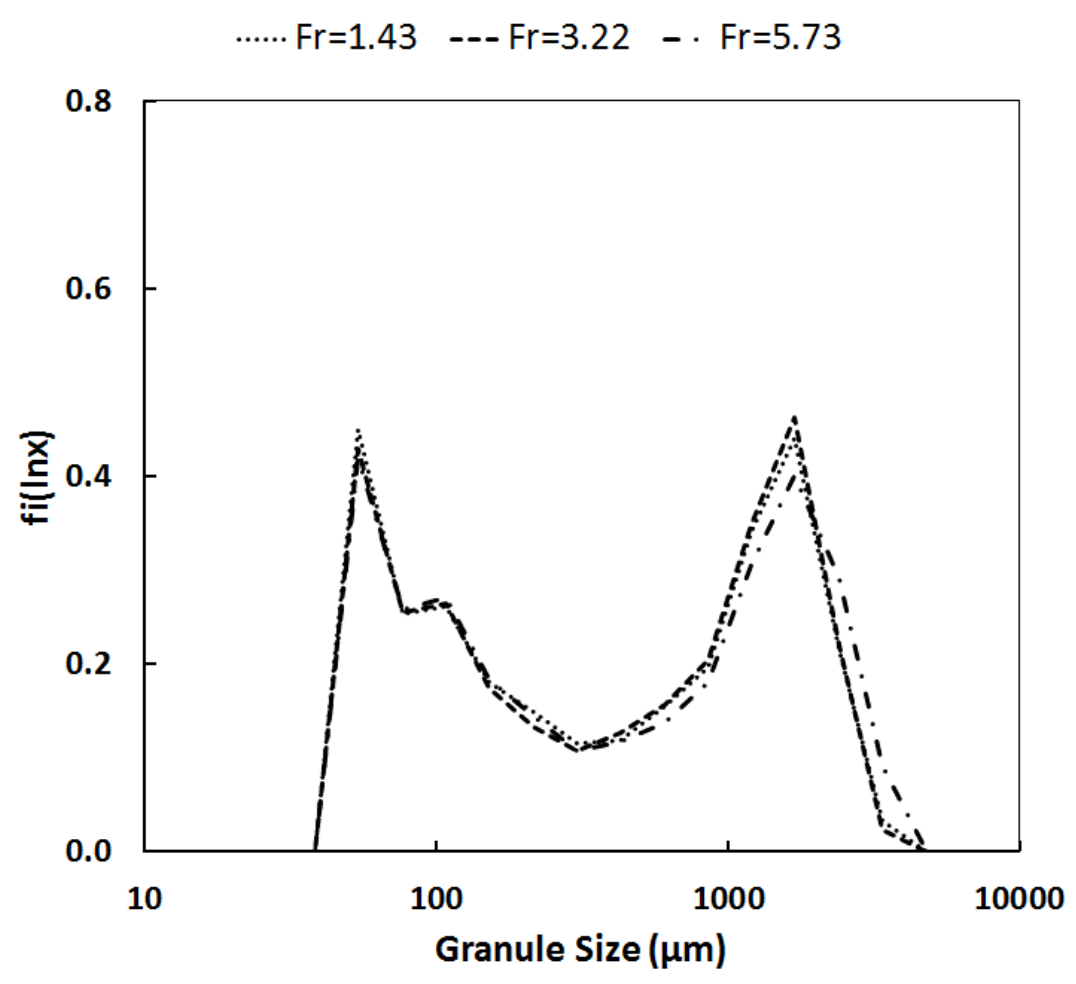

(B)

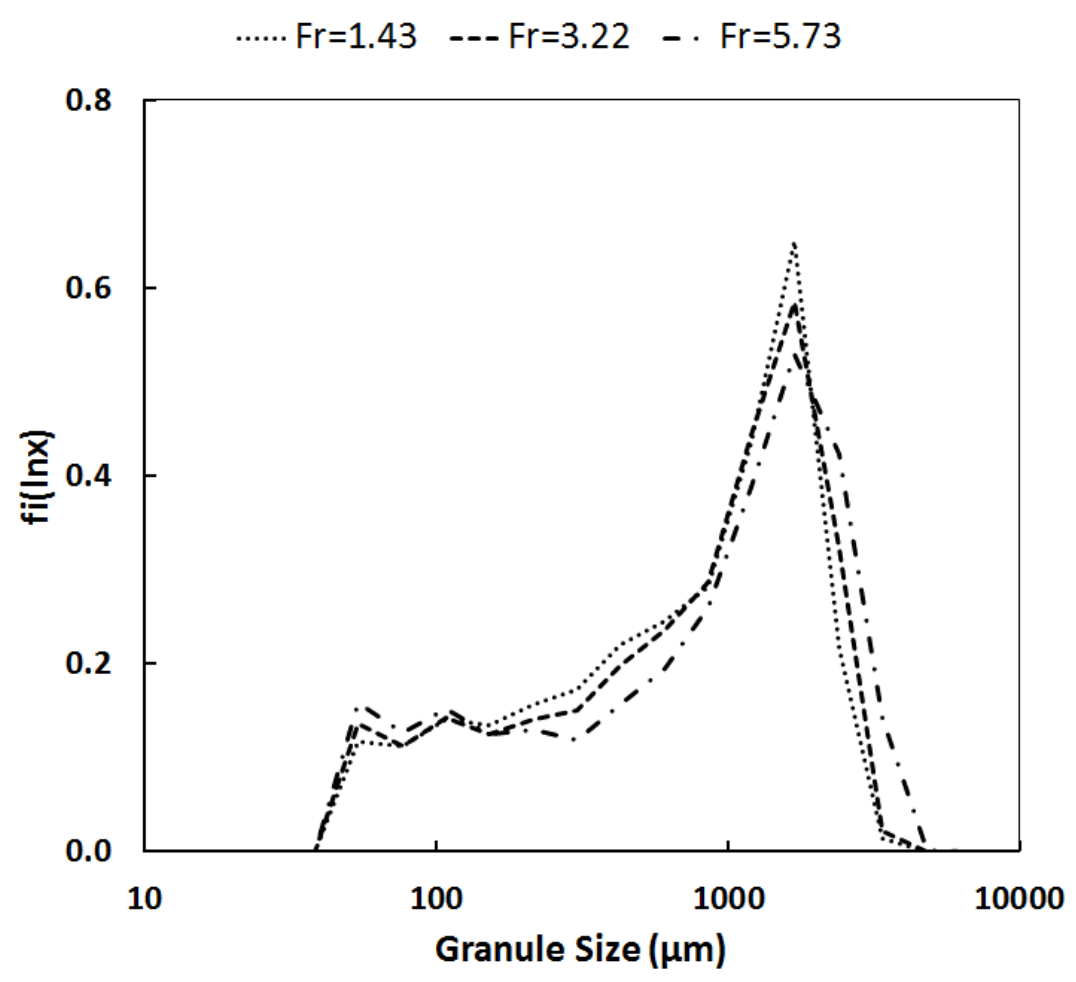

5 Figure $4-$ Effect of $F r$ on granule size distribution for (A) $L S R=0.20$ and (B) $L S R=0.30$. Other parameters: $16 \mathrm{~mm}$ TSG and $P F N=1.30 \times 10^{-2}$ 
(A)

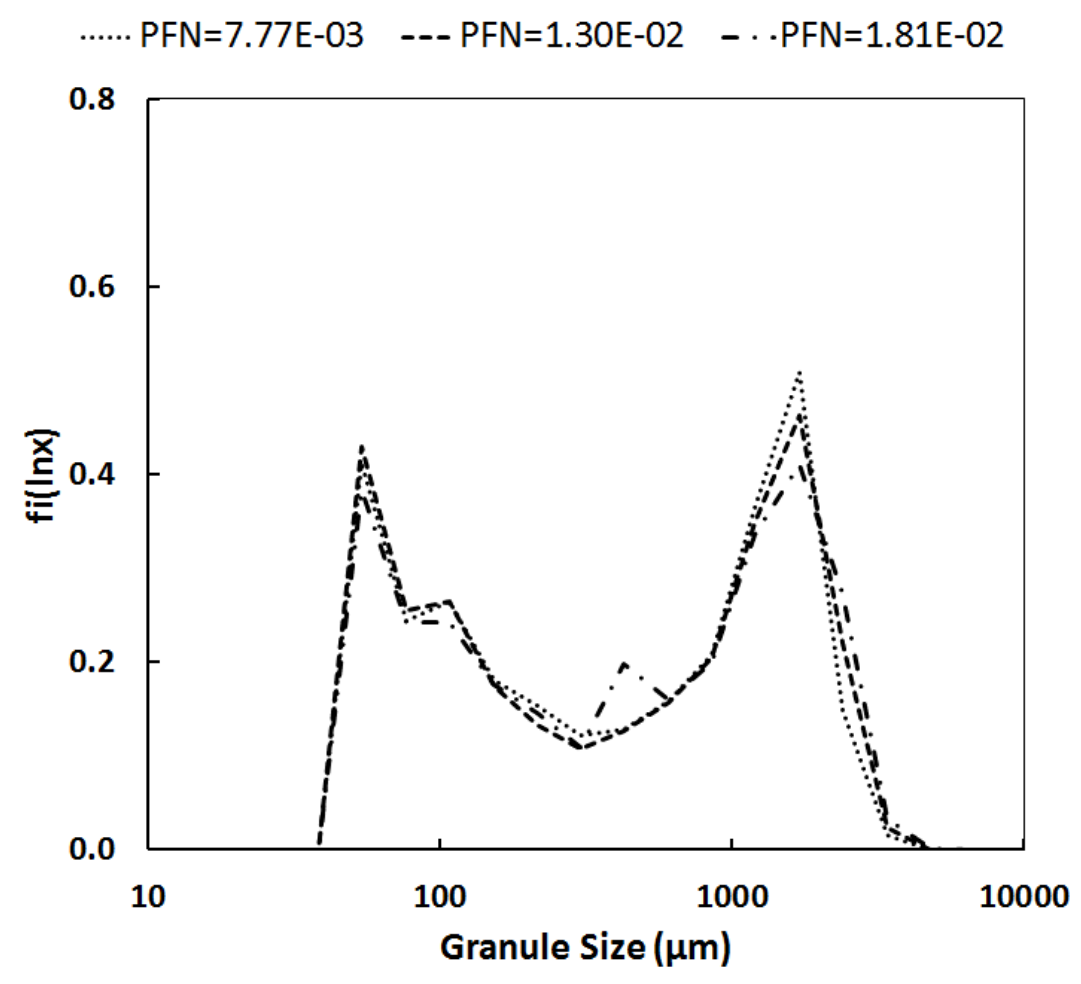

(B)

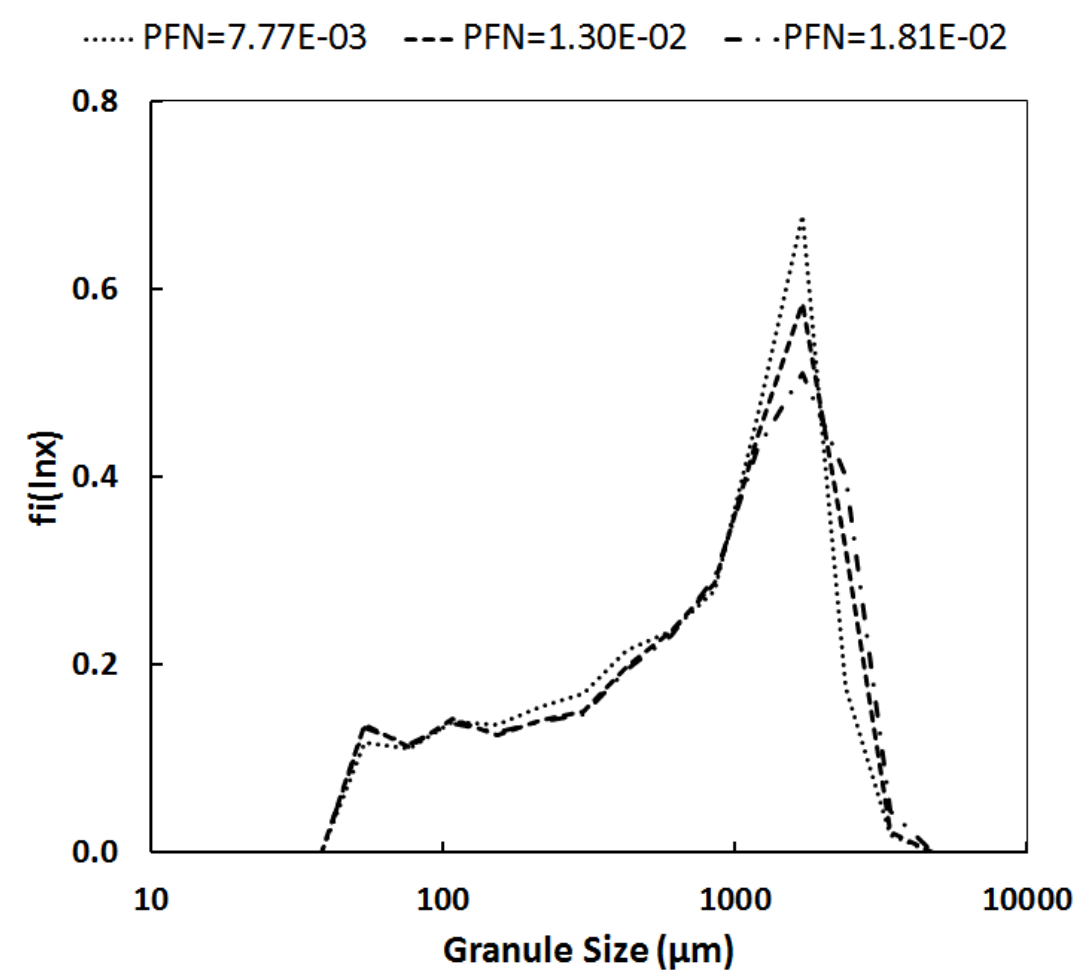

5 Figure 5 - Effect of $P F N$ on granule size distribution for (A) $L S R=0.20$ and (B) $L S R=0.30$. Other parameters: $16 \mathrm{~mm}$ TSG and $F r=3.22$ 
(A)

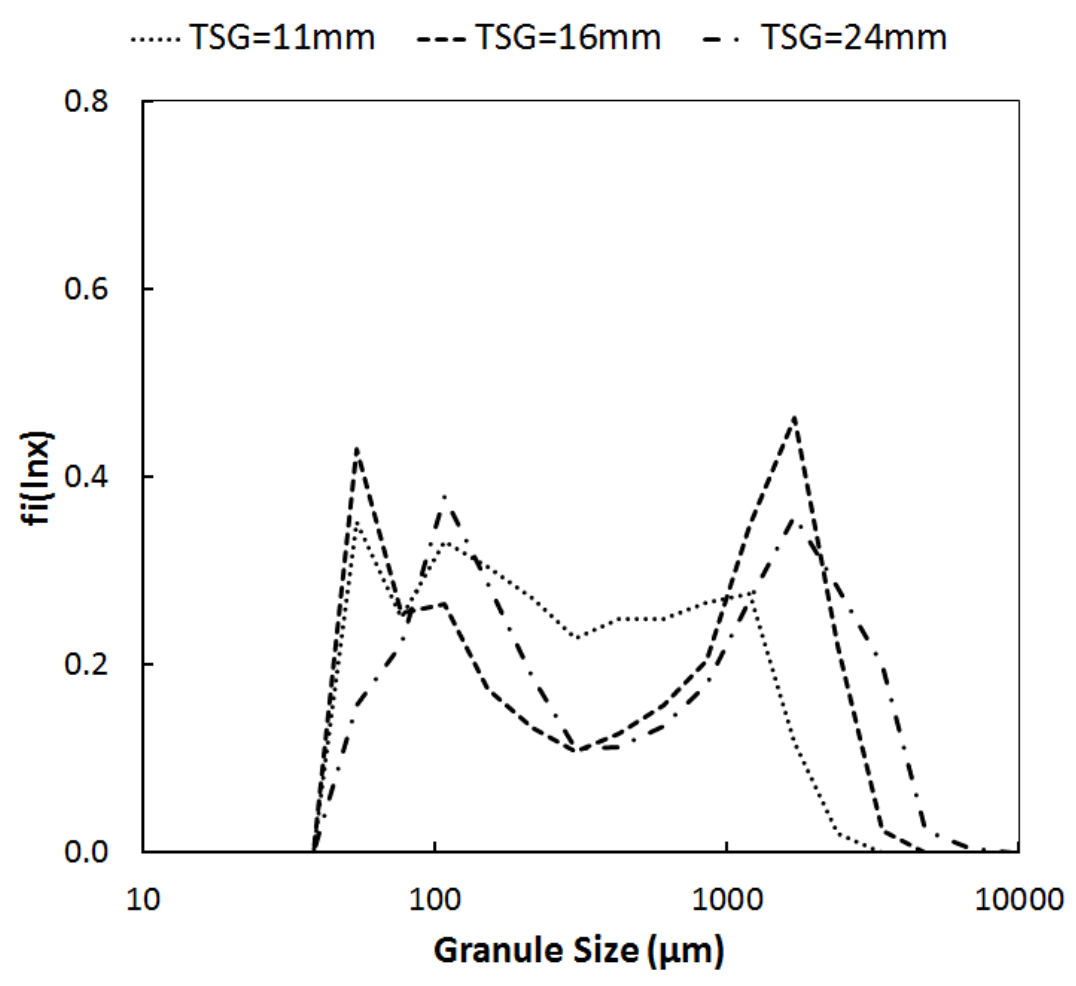

(B)

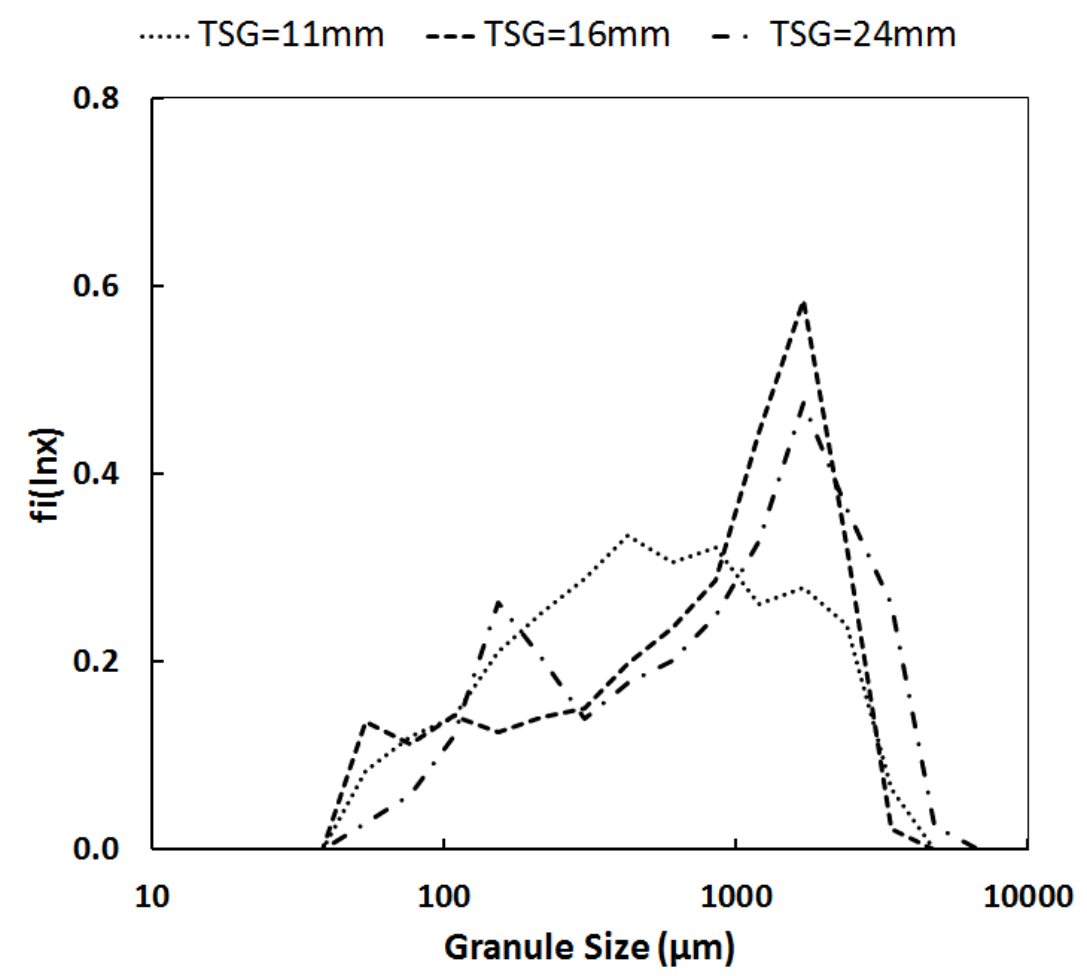

5 Figure 6-Effect of TSG scale on granule size distribution for (A) $L S R=0.20$ and (B) $L S R=0.30$. Other parameters: $F r=3.22$ and $P F N=1.30 \times 10^{-2}$ 


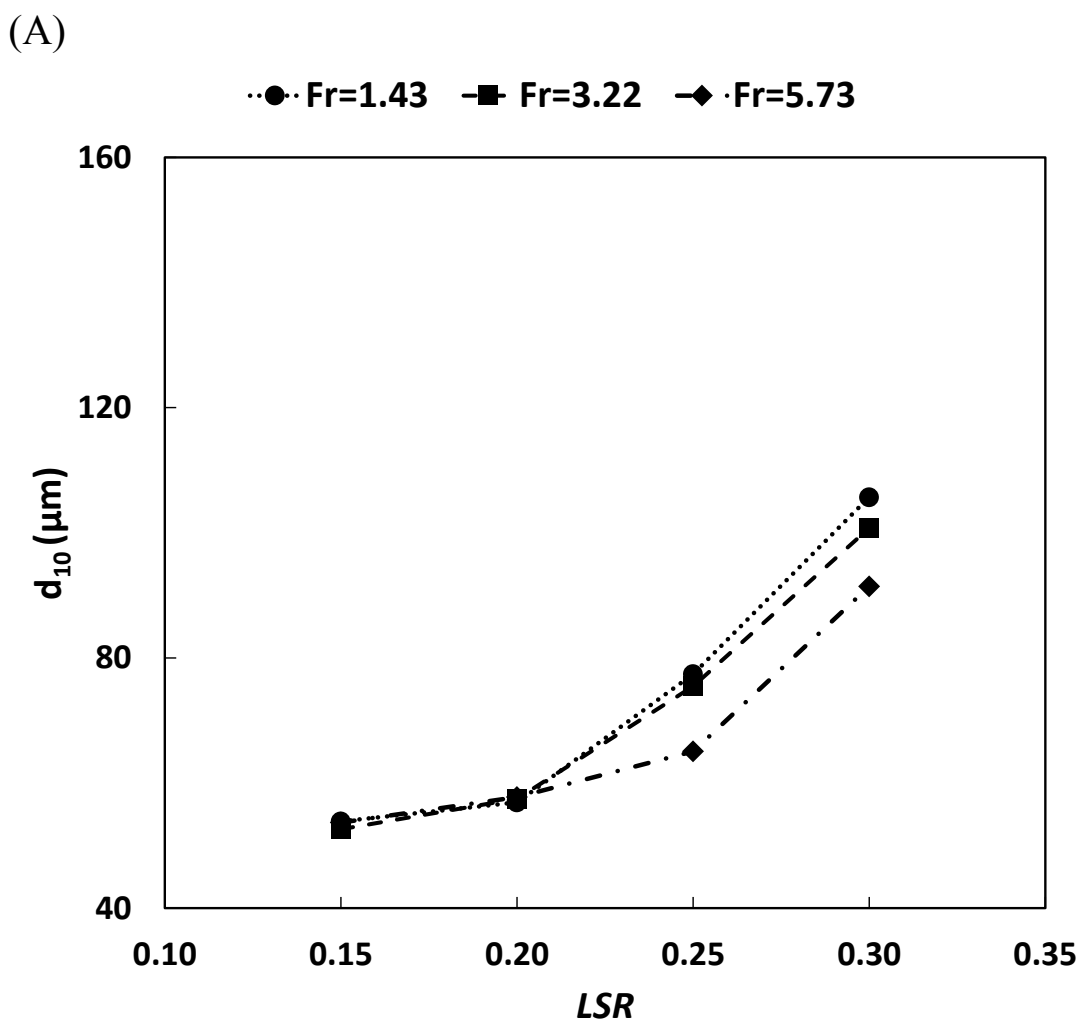

(B)

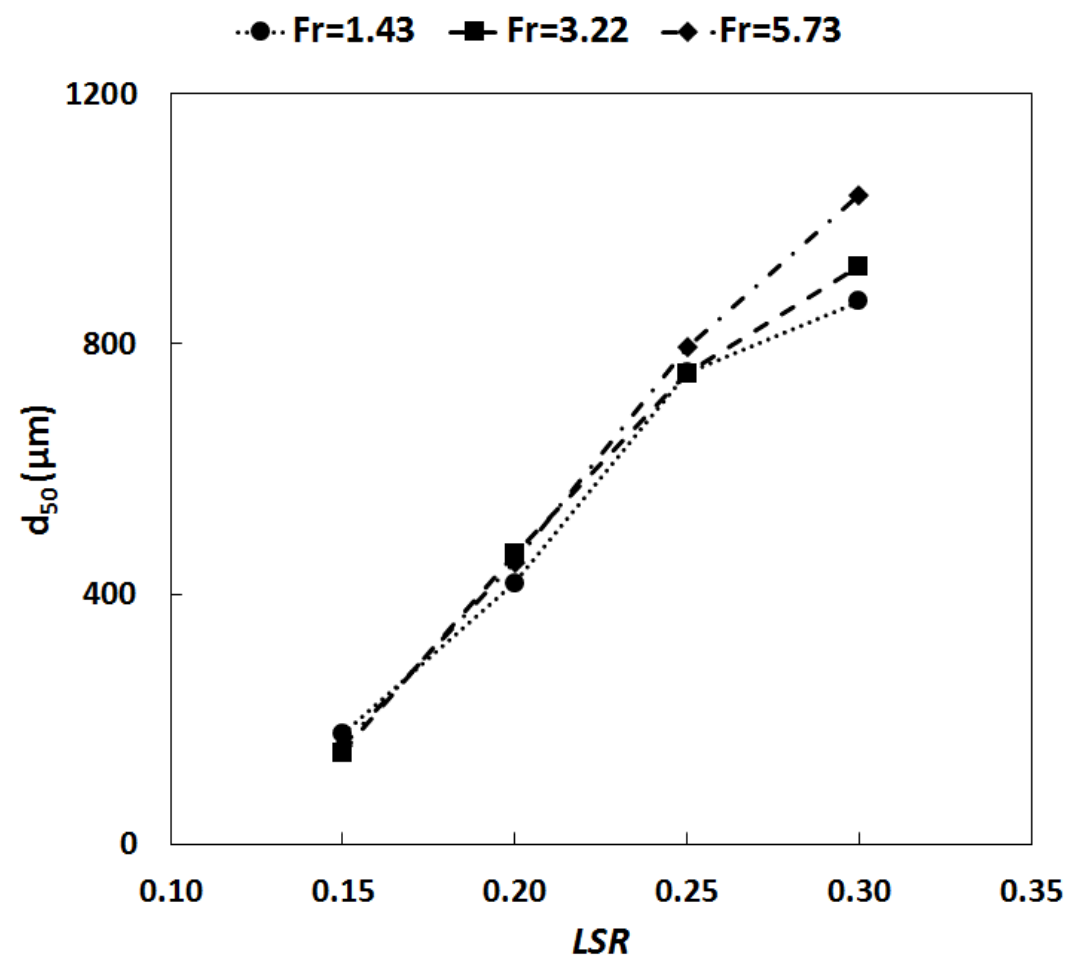




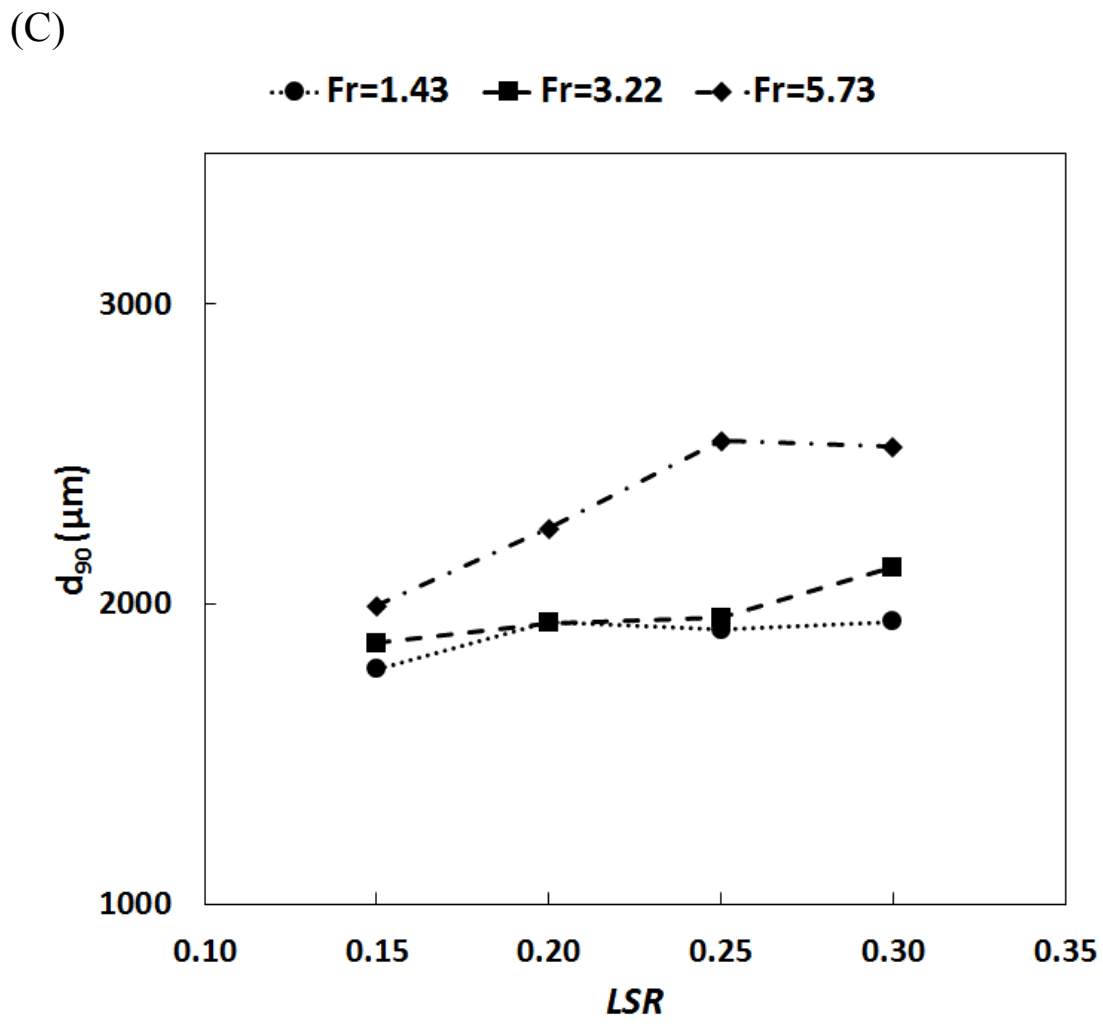

Figure 7 - Effect of $L S R$ and $F r$ on (A) $\mathrm{d}_{10},(\mathrm{~B}) \mathrm{d}_{50}$, and (C) $\mathrm{d}_{90}$. Other parameters: $16 \mathrm{~mm}$ TSG and $P F N=1.30 \times 10^{-2}$

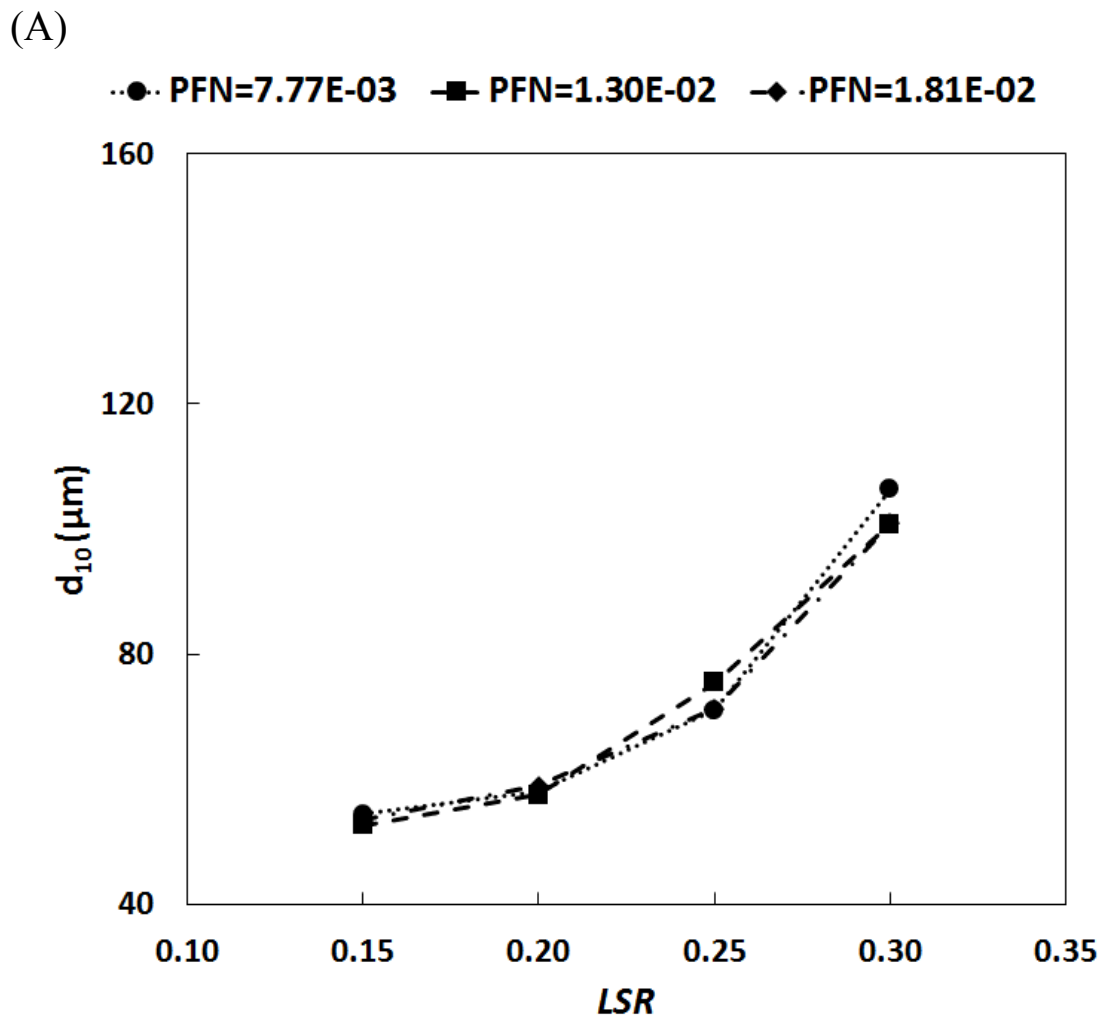


(B)

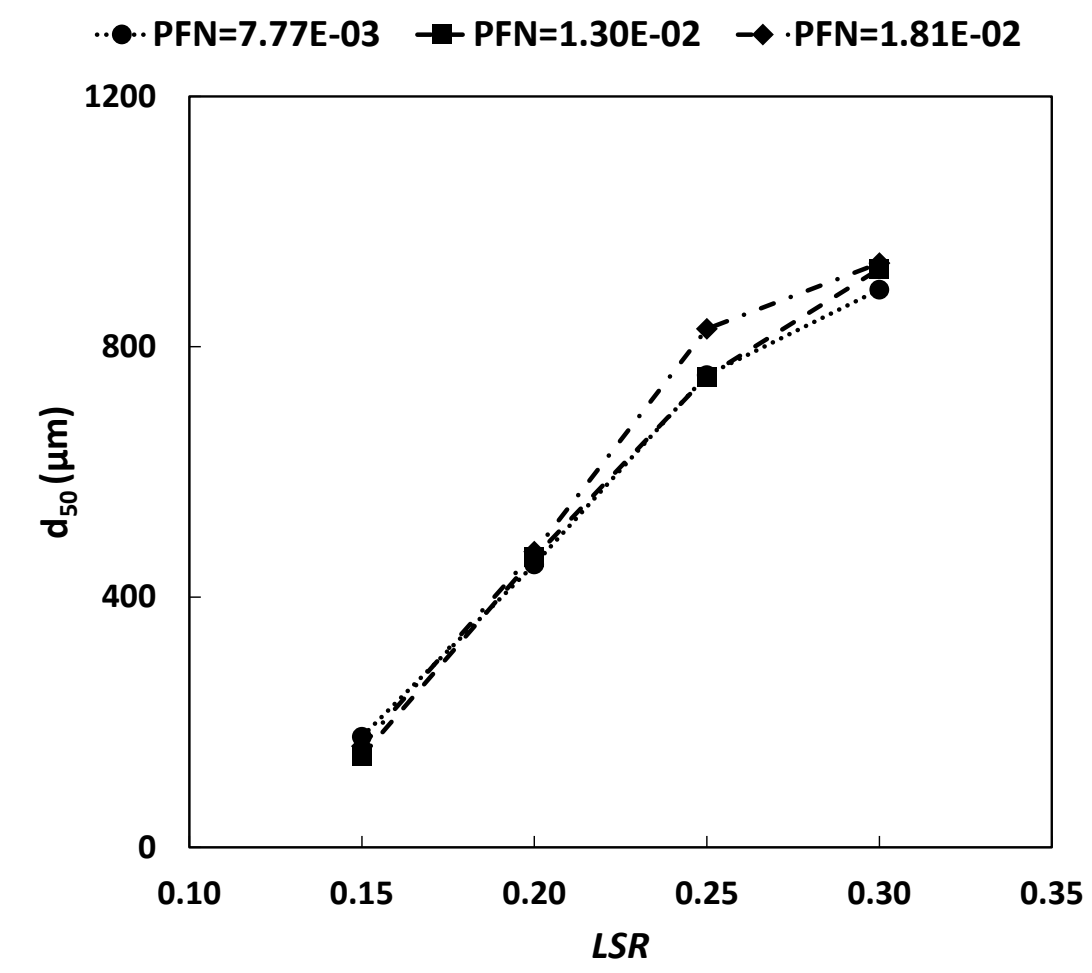

(C)

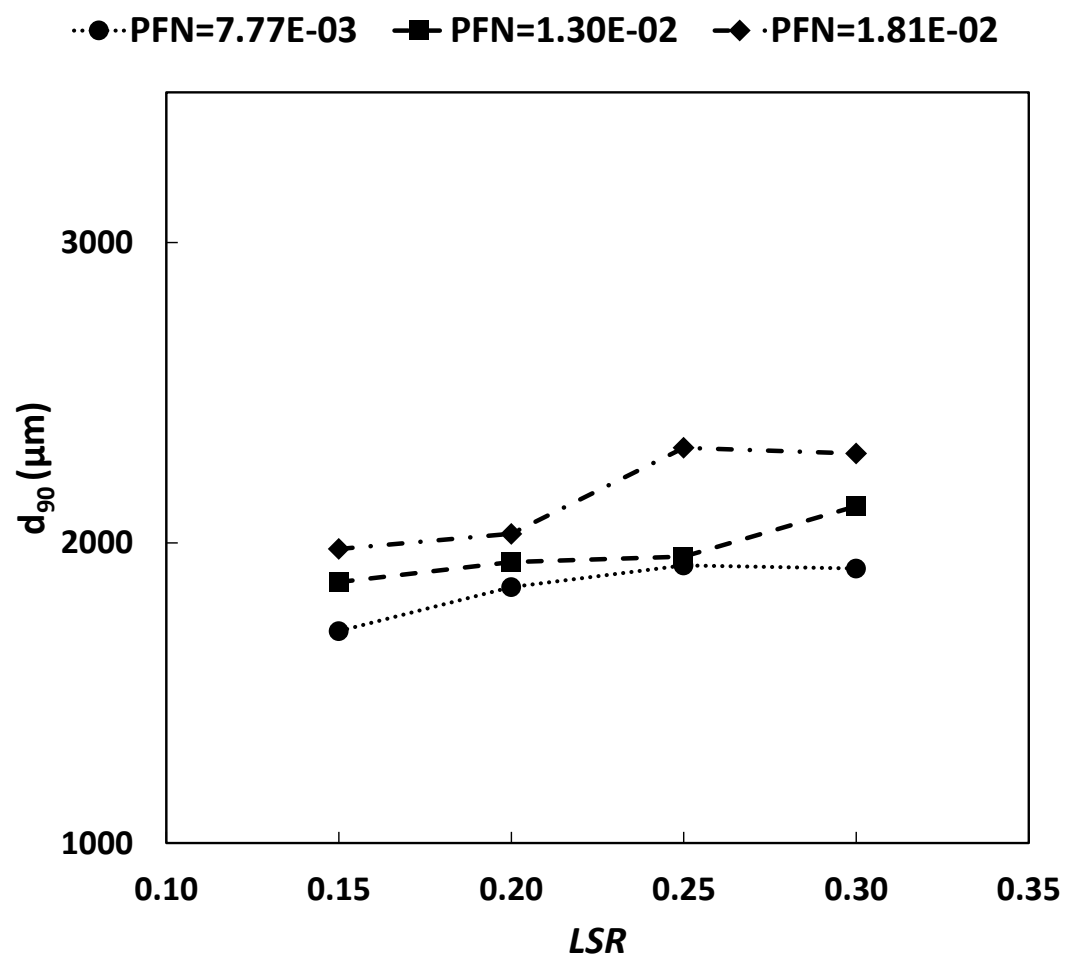

5 Figure 8 - Effect of $L S R$ and $P F N$ on (A) $\mathrm{d}_{10},(B) \mathrm{d}_{50}$, and (C) $\mathrm{d}_{90}$. Particle size analysis for $16 \mathrm{~mm}$ TSG and $F r=3.22$. 
(A)

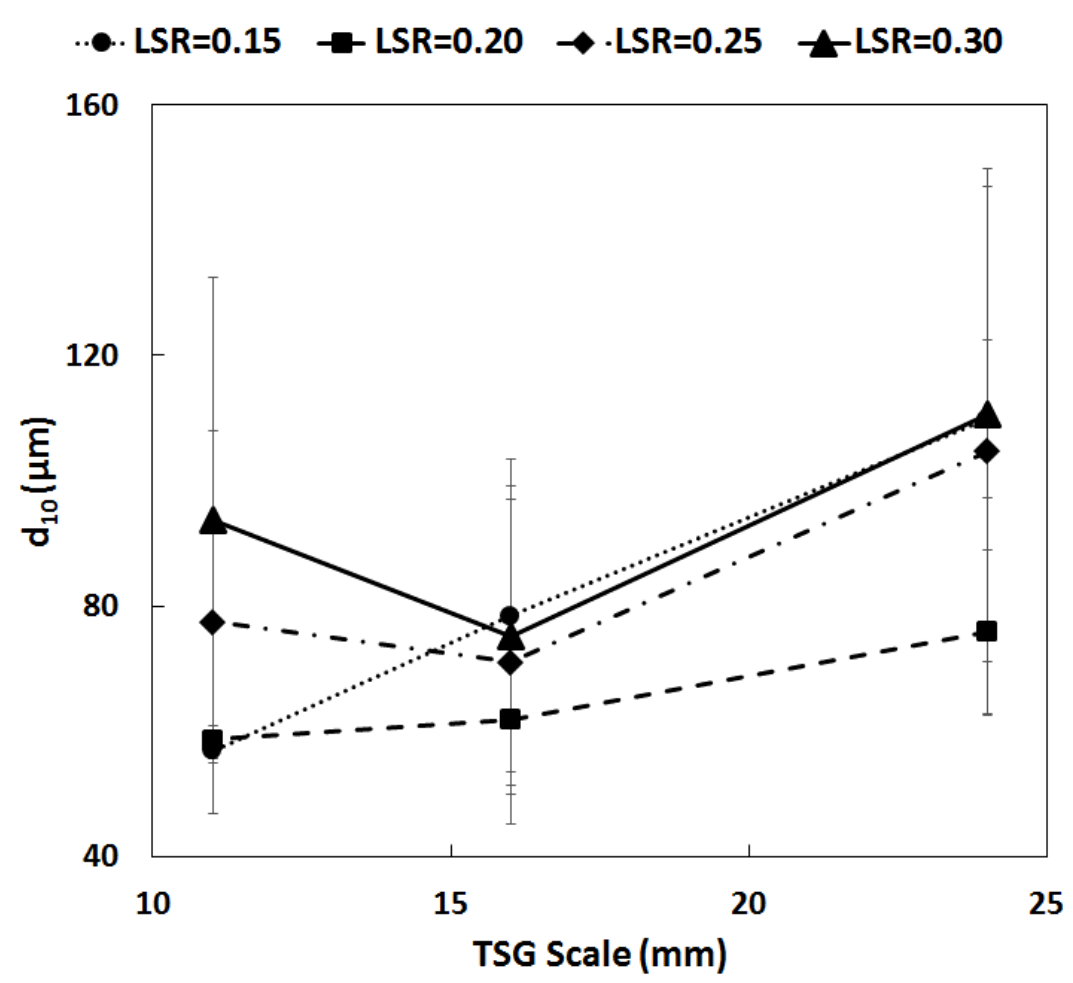

(B)

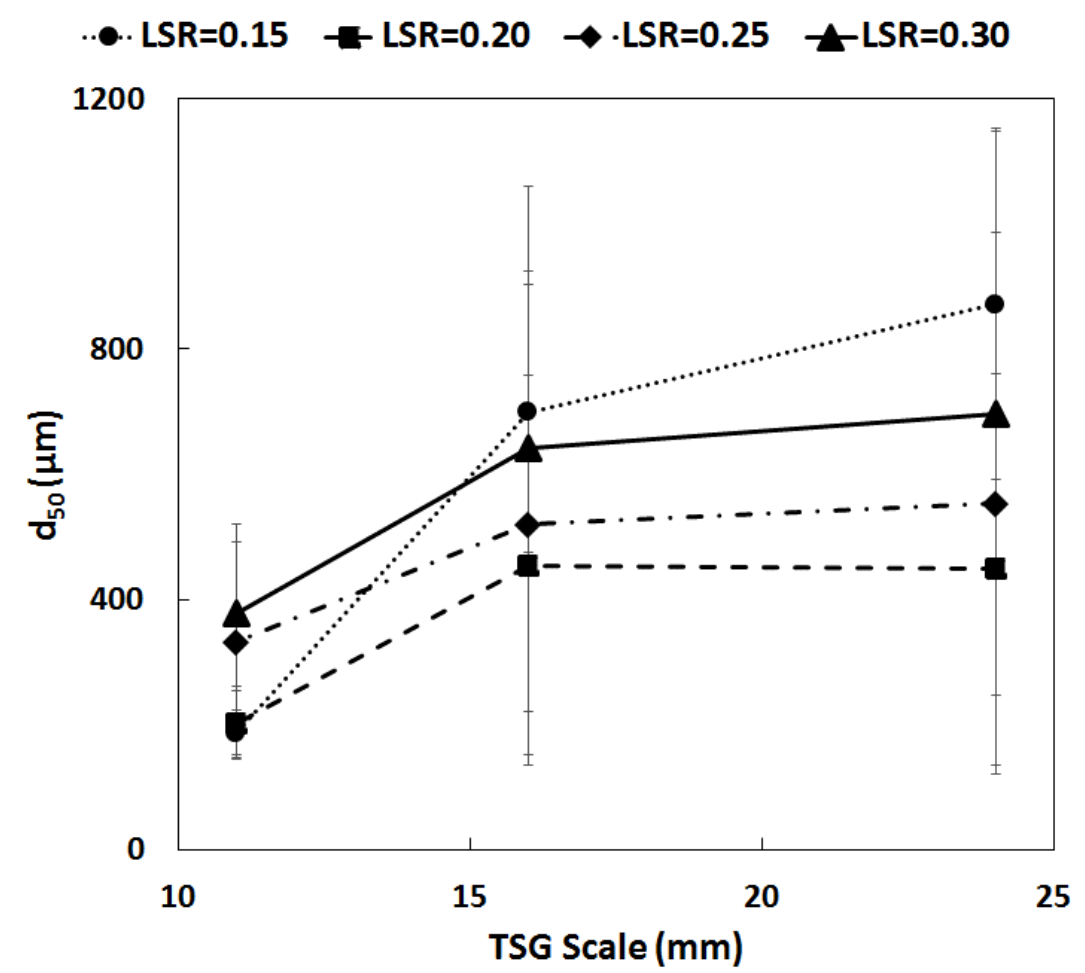


(C)

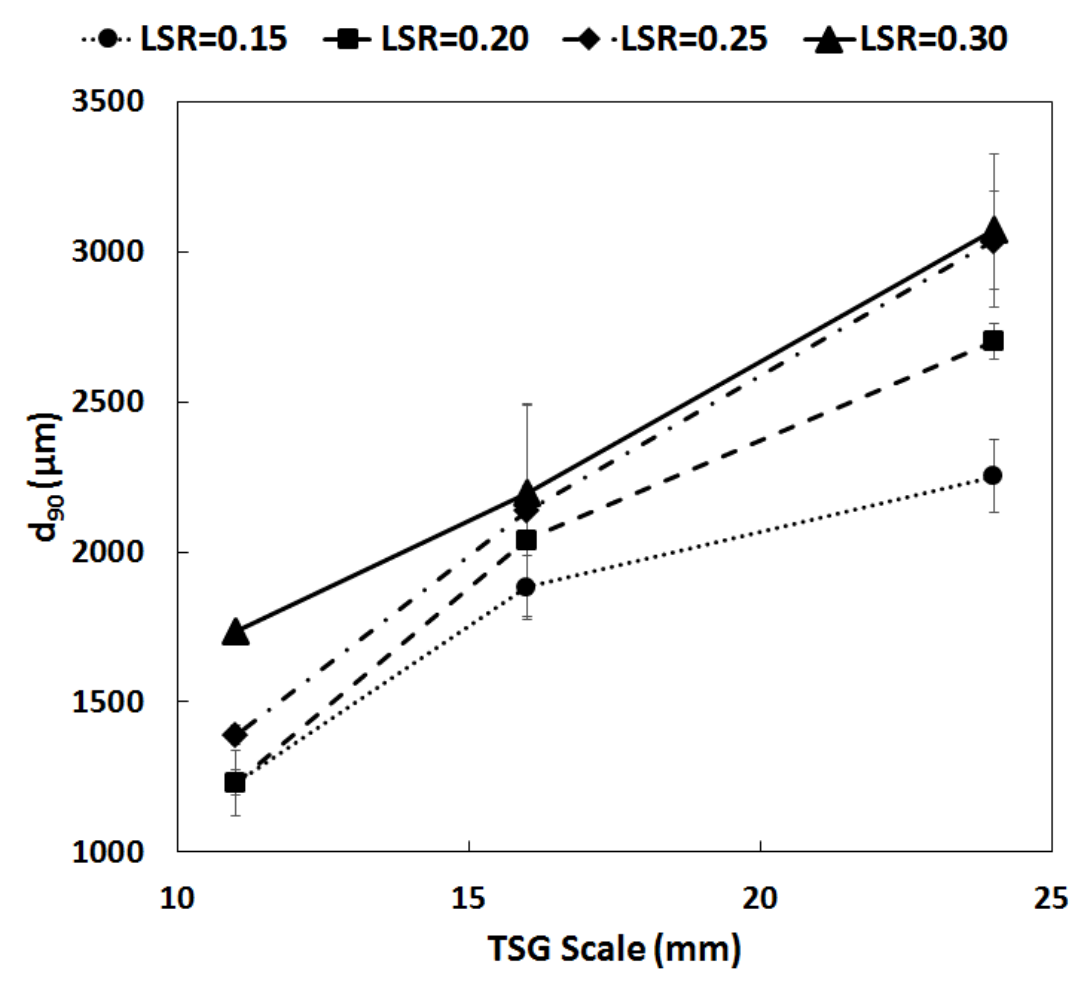

Figure 9 - Effect of TSG scale and $L S R$ and on (A) $\mathrm{d}_{10}$, (B) $\mathrm{d}_{50}$, and (C) $\mathrm{d}_{90}$. Other parameters: Mean values of $F r$ at $P F N=1.30 \times 10^{-2}$

(A) 
(B)

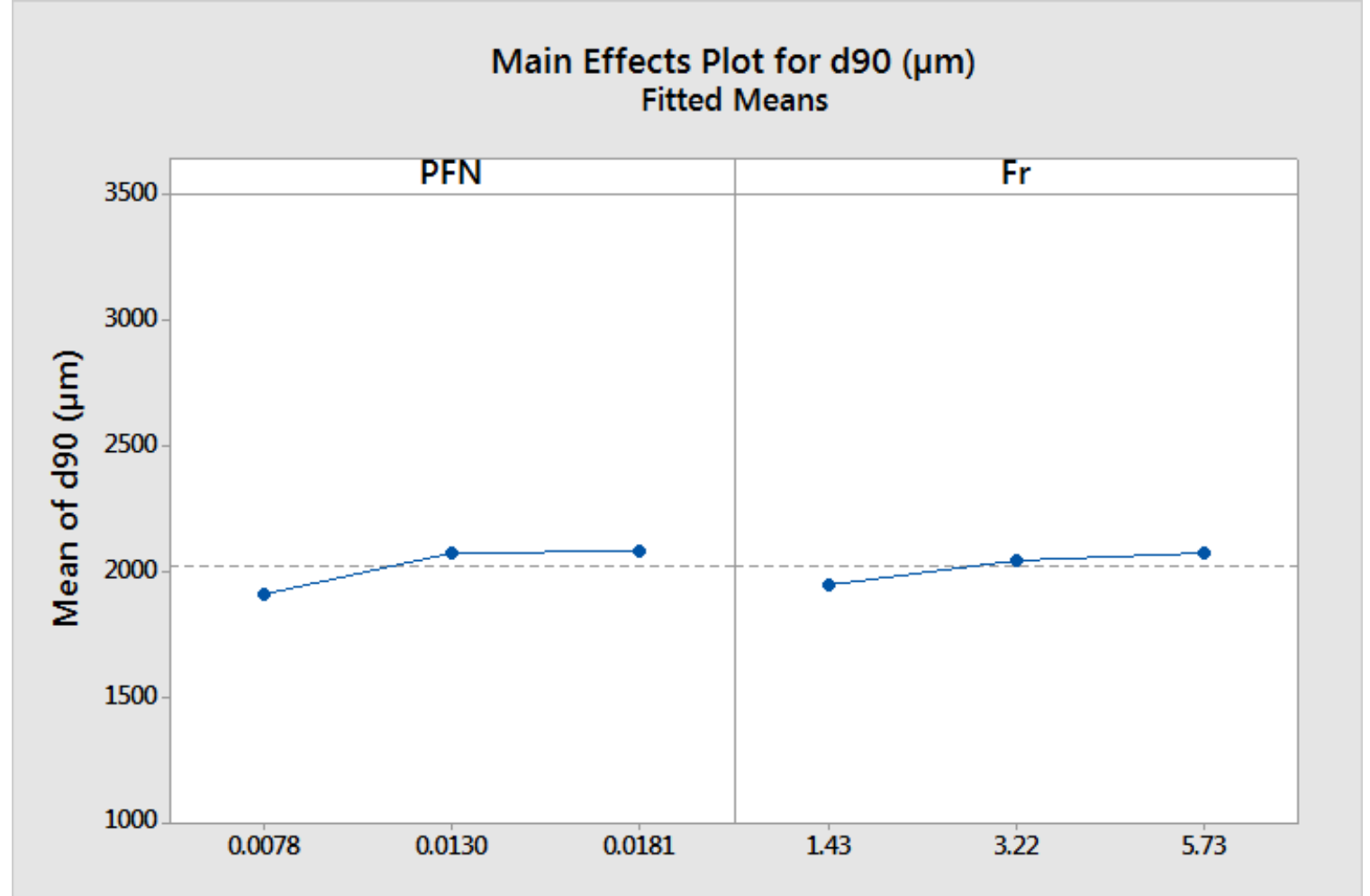

Figure 10 - Main effects of (A) TSG scale and $L S R$ and (B) PFN and Fr on d90 
(A)

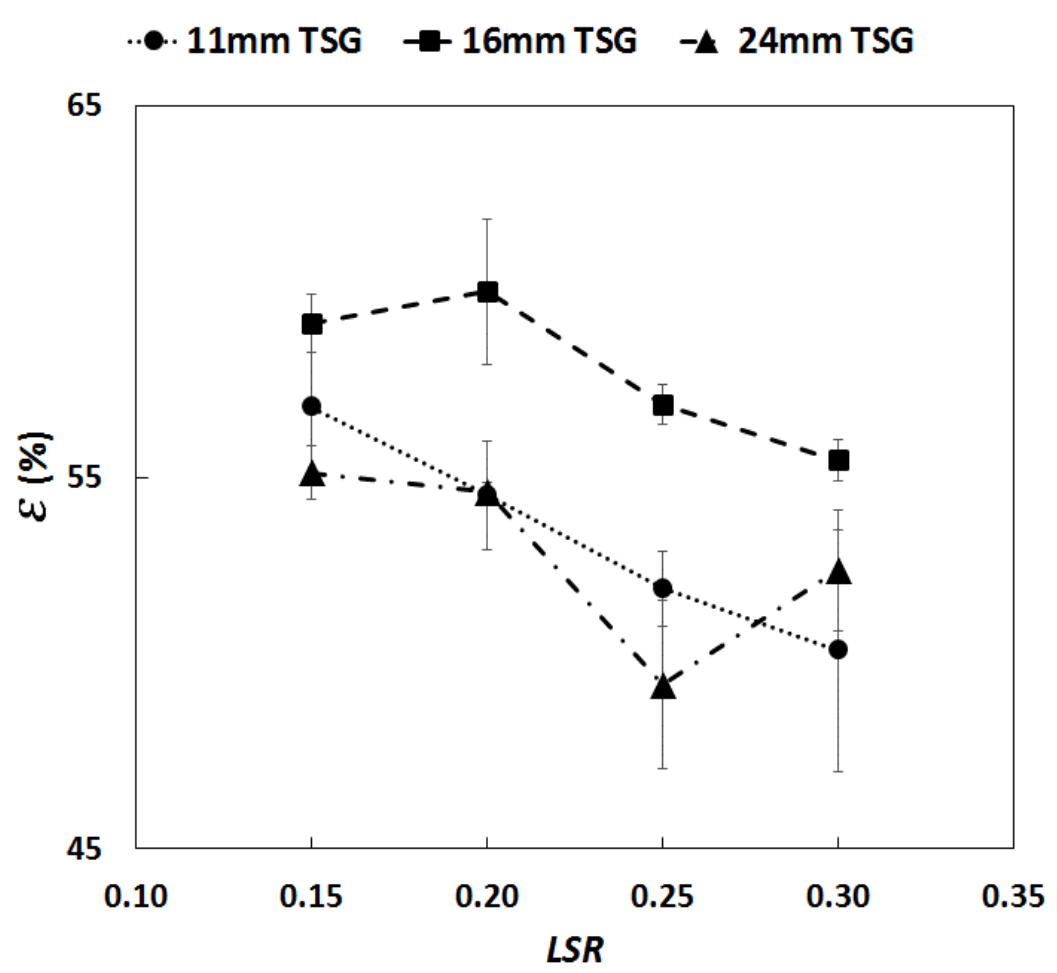

(B)

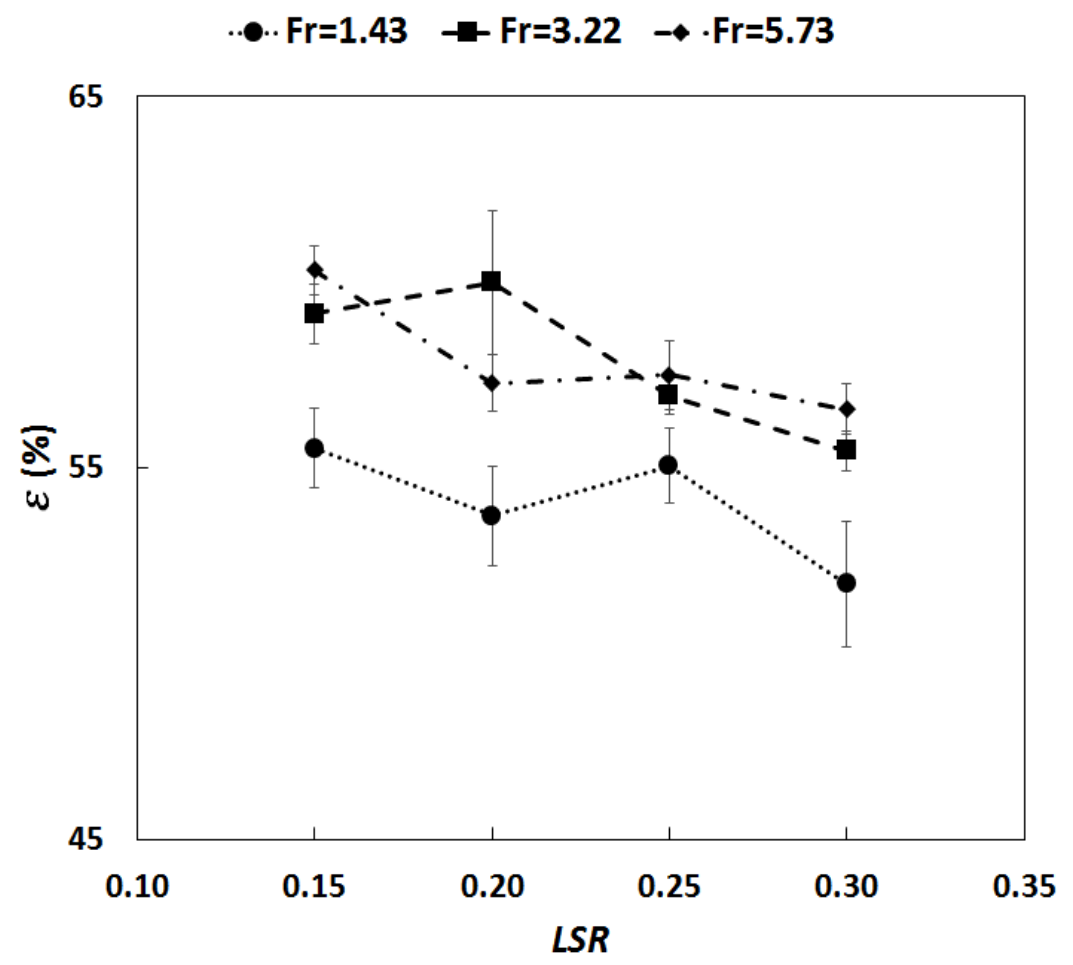


(C)

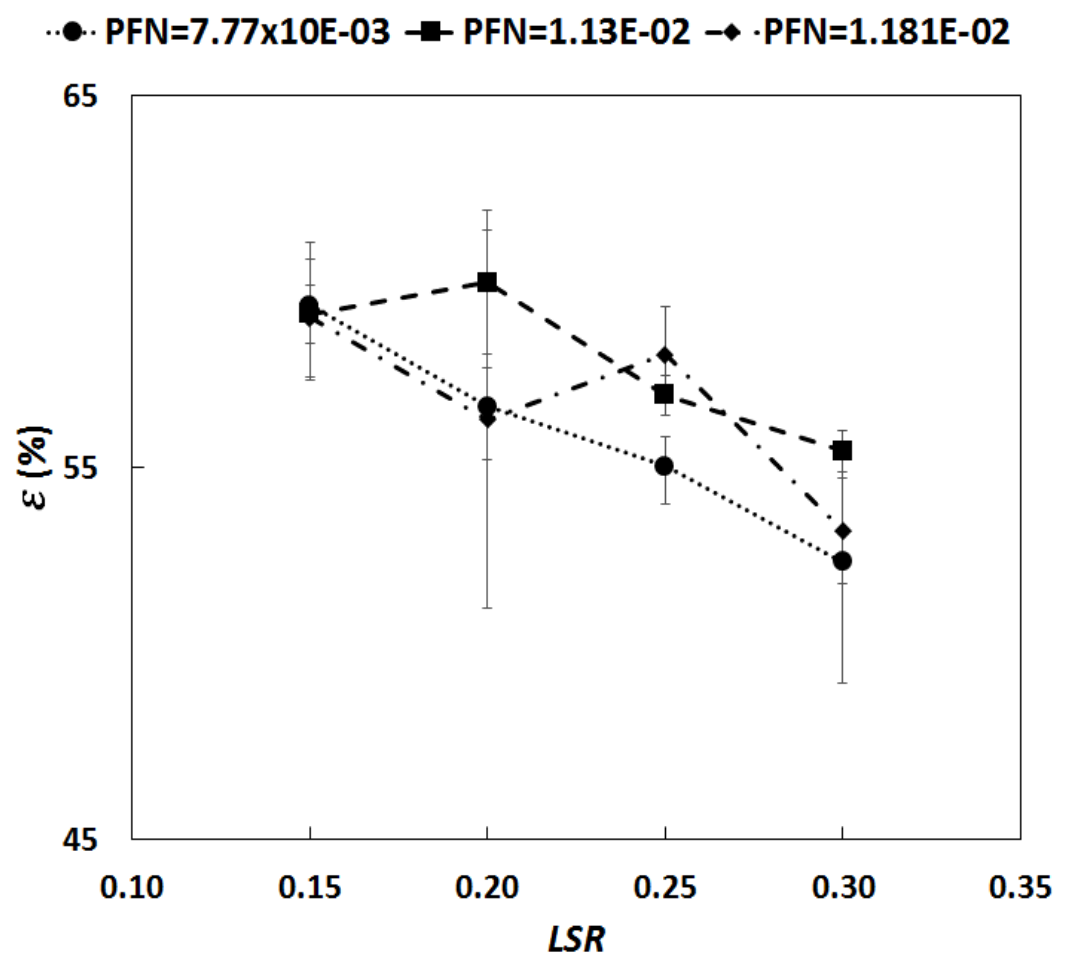

Figure 11 - Effect of (A) $L S R$ and TSG scale on granule porosity $(\varepsilon)$ for $F r=3.22$ and $P F N=1.30 \times 10^{-2}$; (B) $L S R$ and $F r$ on $\varepsilon$ for $16 \mathrm{~mm}$ TSG and $P F N=1.30 \times 10^{-2}$; and (C) $L S R$ and $P F N$ on $\varepsilon$ for $16 \mathrm{~mm}$ TSG 5 and $F r=3.22$

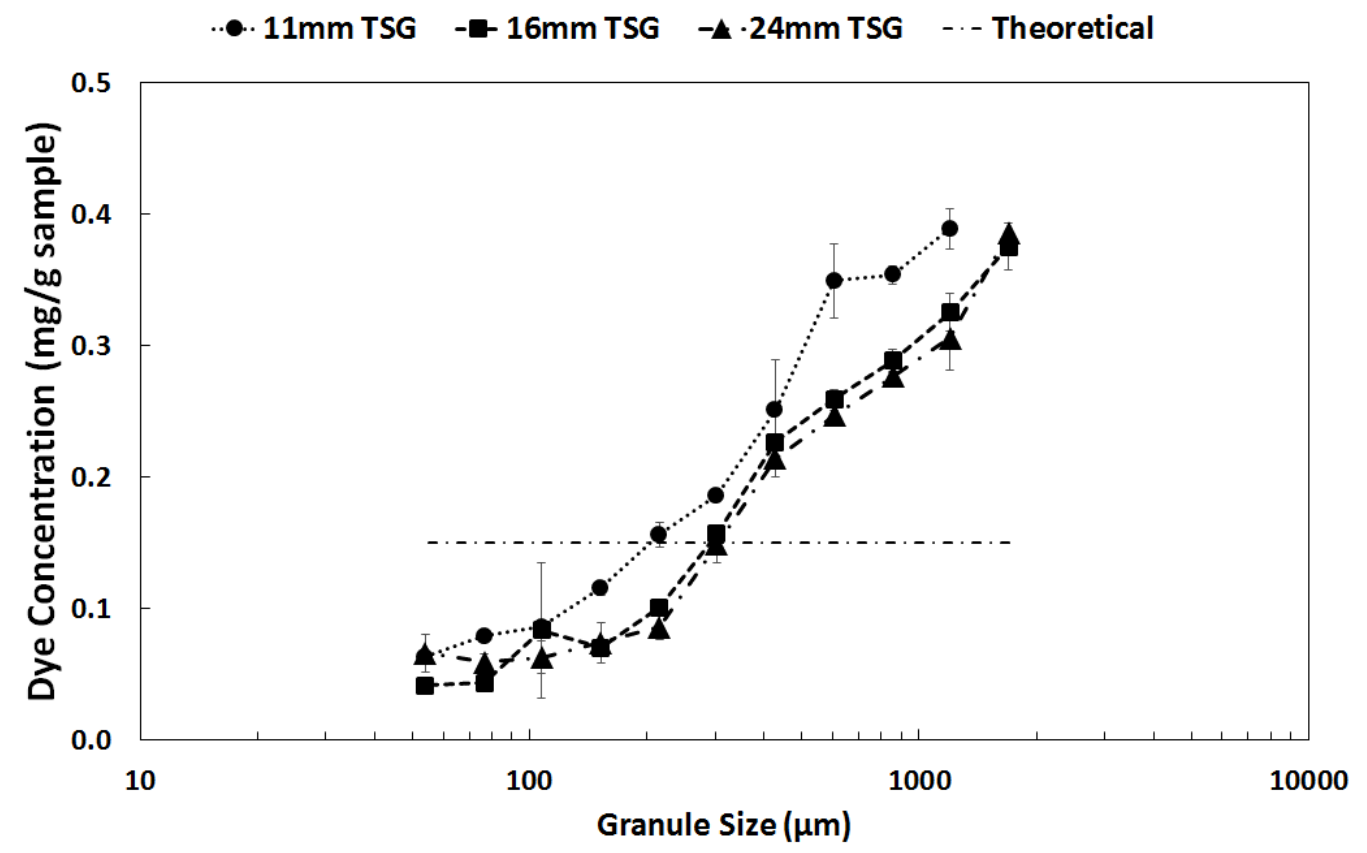

Figure 12 - Effect of TSG scale on liquid distribution (LD) for $L S R=0.15$ at $F r=5.73$ and $P F N$ $=7.77 \times 10^{-3}$ 